\title{
Numerical model for computation of effective and ambient dose equivalent at flight altitudes
}

\section{Application for dose assessment during GLEs}

\author{
Alexander Mishev ${ }^{1, *}$, and Ilya Usoskin ${ }^{1,2}$ \\ 1 ReSoLVE Center of Excellence, University of Oulu, Finland \\ ${ }^{*}$ Corresponding author: alex_mi shev@yahoo.com \\ 2 Sodankylä Geophysical Observatory (Oulu Unit), University of Oulu, Finland
}

Received 8 December 2014 / Accepted 20 April 2015

\begin{abstract}
A numerical model for assessment of the effective dose and ambient dose equivalent produced by secondary cosmic ray particles of galactic and solar origin at commercial aircraft altitudes is presented. The model represents a full chain analysis based on ground-based measurements of cosmic rays, from particle spectral and angular characteristics to dose estimation. The model is based on newly numerically computed yield functions and realistic propagation of cosmic ray in the Earth magnetosphere. The yield functions are computed using a straightforward full Monte Carlo simulation of the atmospheric cascade induced by primary protons and $\alpha$-particles and subsequent conversion of secondary particle fluence (neutrons, protons, gammas, electrons, positrons, muons and charged pions) to effective dose or the ambient dose equivalent. The ambient dose equivalent is compared with reference data at various conditions such as rigidity cut-off and level of solar activity. The method is applied for computation of the effective dose rate at flight altitude during the ground level enhancement of 13 December 2006. The solar proton spectra are derived using neutron monitor data. The computation of the effective dose rate during the event explicitly considers the derived anisotropy i.e. the pitch angle distribution as well as the propagation of the solar protons in the magnetosphere of the Earth.
\end{abstract}

Key words. Atmospheric cascade simulation - Yield function - Effective dose rate - Ambient dose equivalent - Ground level enhancement

\section{Introduction}

Our planet is constantly hit by energetic particles, known as cosmic rays (CRs). Primary CR particles are mostly protons and $\alpha$-particles with a small addition of heavier nuclei. They penetrate deep into the atmosphere, producing large amount of secondary particles via a complicated nuclear-electromagnetic-muon atmospheric cascade. In such a cascade only a fraction of the initial primary particle energy reaches the ground as secondaries. Most of the primary particle's energy is released in the atmosphere by ionization and excitation of the air (Dorman 2004; Bazilevskaya et al. 2008; Usoskin et al. 2009; Vainio et al. 2009). There is a general agreement that the majority of CRs originate from the Galaxy, called galactic cosmic rays (GCRs). Their intensity varies by $10-20 \%$ modulated by the solar wind i.e. it depends on the level of the solar activity. Therefore it follows the 11-year solar cycle and responds to solar-wind variations and transient phenomena (Forbush 1958).

The Earth is also hit sporadically by solar energetic particles (SEPs), which may sometimes produce an atmospheric cascade in a similar way. Solar energetic particles are accelerated during explosive energy releases on the Sun (see Reames 1999; Cliver et al. 2004; Aschwanden 2012, and references therein). While the energy of SEPs is usually of the order of a few tens of $\mathrm{MeV}$, in some cases it can reach a few $\mathrm{GeV}$.
According to a recent study, there is an evidence of possible proton acceleration up to energies in excess of $20 \mathrm{GeV}$ (Bostanjyan et al. 2007). Therefore, they penetrate deep into the atmosphere or even reach the ground, leading to the socalled ground level enhancements (GLEs). Such events occur roughly once a year with a higher probability during a solar maximum (Shea \& Smart 1990). Cosmic ray particles significantly affect the radiation environment and accordingly exposure at commercial flight altitudes, specifically during GLEs (O'Brien et al. 1997; Shea \& Smart 2000, 2012; Spurny et al. 2002). In addition, recently an assessment of thunderstorm radiation environment at aviation flight altitudes has been carried out, which could be significant under some circumstances (Dwyer et al. 2010; Drozdov et al. 2013).

Since aircrews are subject to increased exposure comparing to the sea level due to the increased intensity of secondary CR, the radiation protection of aircrews has been widely discussed. As a result, new regulations appeared, namely Publication 60 of the International Commission on Radiological Protection (ICRP), where the exposure of flying personnel to cosmic radiation is recommended to be regarded as occupational (ICRP 1991). Accordingly in EU, the Euratom Directive 96/12 suggests measures to assess the individual doses of cockpit and cabin crew (EURATOM 1996).

A standard way to assess the exposure is computation based on $\mathrm{CR}$ measurements. In this paper, we describe a 
numerical model to estimate effective and ambient dose equivalent at flight altitudes, based on newly computed yield functions and reconstruction procedure of SEPs based on ground measurements. We focus on dose assessment during GLEs.

\section{Numerical model for computation of effective dose rate and ambient dose equivalent at flight altitude}

Accessment of primary CRs to the Earth atmosphere is influenced by the spatial-temporal variability of complex magnetospheric and interplanetary conditions. Therefore, the task to estimate the air-crew exposure due to CR of galactic and solar origin is not trivial, since it depends on geographic position, altitude and solar activity (Spurny et al. 1996, 2002; Vainio et al. 2009). An assessment of the radiation dose hazard due to CR involves several consecutive steps. In the first step fluxes of GCR and SEPs are determined outside the magnetosphere. Then their propagation through the atmosphere and magnetosphere of the Earth is modelled, resulting in a realistic evaluation of the secondary CR flux. In the work presented here we apply an appropriate magnetospheric model (see below) and new numerically computed yield functions for conversion of the secondary particle fluence to dose (effective/ambient dose equivalent). We also present a convenient procedure for estimation of SEP spectral and angular characteristics based on a neutron monitor data analysis.

\subsection{Definition of the dose rate}

The dose rate can be computed as a function of the geomagnetic rigidity cut-off and altitude using a full Monte Carlo simulation of the atmospheric cascade (Ferrari et al. 2001). At present, several models have been proposed, aiming to estimate the dose rate (effective and/or ambient dose equivalent) at flight altitudes due to primary CR radiation (Schraube et al. 2000; Ferrari et al. 2001; Roesler et al. 2002; Lewis et al. 2005; Matthiä et al. 2008; Sato et al. 2008; Mishev \& Hristova 2012; Mertens et al. 2013; Al Anid et al. 2014; Mishev 2014; Mishev et al. 2015).

According to the definition, the absorbed dose is the energy deposited in a medium by ionizing radiation per unit mass. It is measured as joules per kilogram, i.e. according to SI the unit is Gy. In order to assess the biological risk due to radiation exposure it is convenient to use the effective dose. Since the effective dose is not a measurable quantity, ICRP suggests for operational purpose the ambient dose equivalent (ICRP 2007) denoted as $H^{*}(d)$. It represents the dose equivalent that would be produced by the corresponding expanded and aligned field at a depth $d$ in an International Commission on Radiation Units and Measurements (ICRU) sphere (a sphere with diameter of $30 \mathrm{~cm}$ made of tissue equivalent material with a density of $1 \mathrm{~g} \mathrm{~cm}^{3}$ and a mass composition of $76.2 \%$ oxygen, $11.1 \%$ carbon, $10.1 \%$ hydrogen and $2.6 \%$ nitrogen) on the radius vector opposing the direction of the aligned field. The unit for both effective dose and ambient dose equivalent is Sv. According to recent studies the ambient dose equivalent at a depth of $d=10 \mathrm{~mm} H^{*}(10)$ is recommended as a reasonable proxy for the effective dose (Pelliccioni 2000). In general it slightly overestimates the effective dose. However, it is not a conservative estimate for cosmic radiation exposure at aviation altitudes according to Mertens et al. (2013) and the work presented here, specifically in high rigidity regions. Nevertheless, it is regarded as an acceptable approximation for effective dose at aircraft altitudes (Meier et al. 2009; Mertens et al. 2013).

\subsection{Formalism}

The effective dose rate at a given atmospheric depth $h$ induced by a primary $\mathrm{CR}$ particle can be determined as:

$$
E\left(h, \lambda_{m}, \theta, \varphi\right)=\sum_{i} \int_{T^{\prime}\left(\lambda_{m}\right)}^{\infty} \int_{\Omega} J_{i}\left(T^{\prime}\right) Y_{i}\left(T^{\prime}, h\right) d \Omega \mathrm{d} T^{\prime},
$$

where $T^{\prime}$ is the energy of the primary CR particle arriving from zenith angle $\theta$ and azimuth angle $\varphi, J_{i}\left(T^{\prime}\right)$ is the differential energy spectrum of the primary CR at the top of the atmosphere for $i$ component (proton and/or $\alpha$-particle), $\lambda_{m}$ is the geomagnetic latitude, $\Omega(\theta, \varphi)$ is a solid angle and $Y_{i}$ is the effective dose yield function.

Accordingly, the effective dose yield function $Y_{i}$ is defined as:

$$
Y_{i}\left(T^{\prime}, h\right)=\sum_{j} \int_{T^{*}} F_{i, j}\left(h, T^{\prime}, T^{*}, \theta, \varphi\right) C_{j}\left(T^{*}\right) \mathrm{d} T^{*},
$$

where $C_{j}\left(T^{*}\right)$ is the fluence to effective dose conversion coefficient for a secondary particle of type $j$ (neutron, proton, $\gamma$, $\left.e^{-}, e^{+}, \mu^{-}, \mu^{+}, \pi^{-}, \pi^{+}\right)$with energy $T^{*}, F_{i, j}\left(h, T, T^{*}, \theta, \varphi\right)$ is the secondary particle fluence of type $j$, produced by a primary particle of type $i$ (proton and/or $\alpha$-particle) with a given primary energy $T^{\prime}$. The conversion coefficients $C_{j}\left(T^{*}\right)$ (see Pelliccioni 2000; Petoussi-Henss et al. 2010, and references therein) for a secondary particle of type $j$ are obtained on the basis of extensive Monte Carlo simulations with various codes including a precise cross-check, namely: FLUKA (Fasso et al. 2005; Battistoni et al. 2007), MCNPx (Briesmeister 1997; Waters et al. 2007), PHITS (Iwase et al. 2002), GEANT4 (Agostinelli et al. 2003) and EGSnrc (Kawrakow 2001) performed by the DOCAL task Group assuming a reference computational phantom (ICRP 2009). The secondary particle fluence at a given altitude above the sea level (a.s.l.) is obtained here with extensive simulations of the atmospheric cascade with GEANT4 (Agostinelli et al. 2003) based PLANETOCOSMICS code (Desorgher et al. 2005) assuming a realistic atmo spheric model NRLMSISE2000 (Picone et al. 2002). Here we assume an isotropic secondary particle flux, which is in good agreement with a realistic case for aircrew dosimetry (Sato et al. 2011). The atmospheric cascade simulations have been performed in a wide energy range, namely between $0.5 \mathrm{GeV} /$ nucleon and $1 \mathrm{TeV} /$ nucleon for primary protons and $\alpha$-particle, assuming isotropic particle incidence. The effective dose yield function considers explicitly the complexity of the atmospheric cascade development, since it brings information of particle fluence and spectrum at a given altitude in the atmosphere, considering explicitly the secondary particle attenuation.

Accordingly, the ambient dose equivalent $H^{*}(10)$ i.e. the dose equivalent produced at a depth of $10 \mathrm{~mm}$ in a ICRU sphere, at given atmospheric altitude $h$ induced by a primary cosmic ray particle can be determined as:

$$
H^{*}(10)=\sum_{i} \int_{T^{\prime}\left(\lambda_{m}\right)}^{\infty} \int_{\Omega} J_{i}\left(T^{\prime}\right) Y_{i}^{*}\left(T^{\prime}, h\right) d \Omega \mathrm{d} T^{\prime},
$$

where $Y_{i}^{*}\left(T^{\prime}\right)$ is the ambient dose equivalent yield function determined in a way similar to Eq. (2). Here we adopt the data sets for an isotropic particle fluence from Appendix 2 of Pelliccioni (2000) i.e. the fluence to ambient dose 


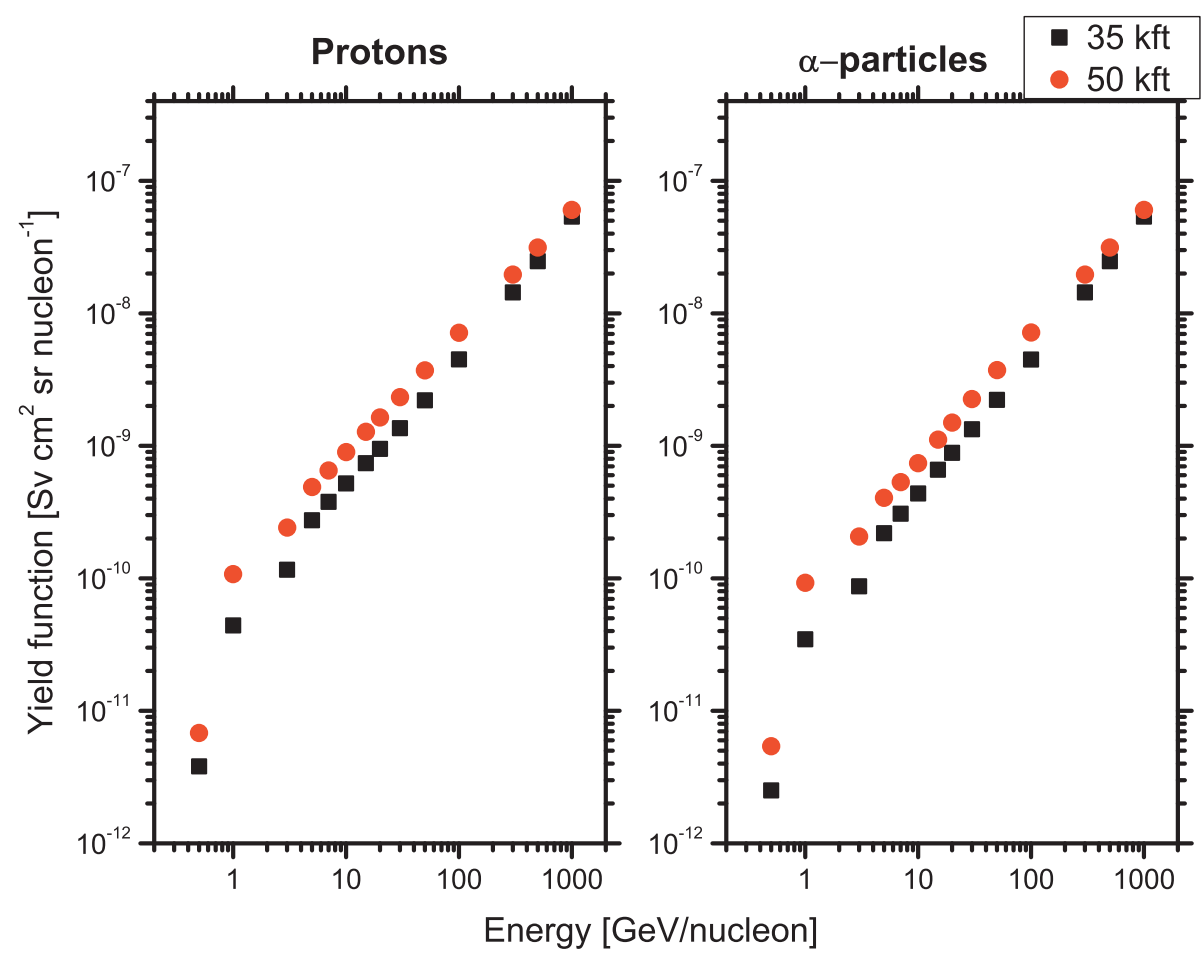

Fig. 1. Effective dose yield function as a function of the energy per nucleon for primary CR protons and $\alpha$-particles at two different altitudes a.s.l., namely $35 \mathrm{kft}$ (typical commercial flight $\approx 10.5 \mathrm{~km}$ ) and $50 \mathrm{kft}$ (supersonic flight $\approx 15 \mathrm{~km}$ ).

equivalent conversion coefficients for the described above secondaries. Accordingly the fluence to ambient dose equivalent conversion coefficients is obtained using Monte Carlo simulations with the FLUKA code (Fasso et al. 2005; Battistoni et al. 2007).

Yield functions for the effective dose for primary protons and $\alpha$-particles at altitude of $35 \mathrm{kft}$ (typical commercial flights $\approx 10.5 \mathrm{~km}$ ) and altitude of $50 \mathrm{kft}$ (supersonic flights $\approx 5 \mathrm{~km}$ ) are presented in Figure 1 with details given in Table A.1 of Appendix A. Accordingly, Table A.2 gives details for the ambient dose equivalent yield function. For a realistic interpretation of SEP with oblique particle incidence we present also effective dose yield function for primary protons with vertical and $15^{\circ}, 30^{\circ}$ and $\theta=45^{\circ}$ incidence (Clem 1997; Cramp et al. 1997; Vashenyuk et al. 2006). Accordingly, the details are given in Table A.3.

As mentioned above, it is necessary to have a precise model for the CR spectrum. Here we use a force field model for the GCR (see below). Since the flux and spectra of SEPs vary considerably between solar eruptive events, we describe below a method for determination of their spectral and angular characteristics based on neutron monitor (NM) data.

\subsection{GCR spectrum}

A detailed description of force field model for GCR spectrum is given elsewhere (Usoskin et al. 2005). The GCR flux is affected by the interplanetary magnetic field and solar wind. It results in modulation of GCR in the vicinity of the Earth. The modulation varies with solar activity (Gleeson \& Axford 1968; Caballero-Lopez \& Moraal 2004). The only explicit parameter of this model is the modulation potential $\phi$ given in units of MV. The value of $Z e \phi$ ( $Z$ is the charge number) corresponds to the average energy loss of cosmic rays inside the heliosphere. Here we consider the nucleonic ratio of heavier particles including $\alpha$-particles to protons in the interstellar medium as 0.3 (Gaisser \& Stanev 2010) similarly to Kovaltsov et al. (2012). The model with the corresponding parametrization of LIS provides very good fitting of the measured spectra (for details see Usoskin et al. 2005, and references therein). For the computations, a realistic mass composition of the primary GCR (Gaisser \& Stanev 2010) is assumed, where the contribution of heavier species is scaled to that for $\alpha$-particles (Usoskin \& Kovaltsov 2006; Mishev \& Velinov 2011; Kovaltsov et al. 2012).

\subsection{Model of the Earth magnetosphere}

Both GCR and SEPs are shielded by the geomagnetic field. The shielding is most effective near the geomagnetic equator and absent close to the geomagnetic poles. The capacity of the shielding is approximately quantified by the effective vertical rigidity cut-off $R_{c}$, which varies with the geographical location (Cooke et al. 1991).

Since the precise particle propagation in the magnetosphere is important for both GLE analysis and access of SEPs, which typically possess an essential anisotropic part, to a given location, a realistic geomagnetospheric model is necessary (Smart et al. 2000; Desorgher et al. 2009; Mishev \& Usoskin 2013). Several models, tools, algorithms to calculate geomagnetic cut-off rigidity, particle trajectories and the asymptotic viewing cones were proposed during the years (McCracken et al. 1962, 1968; Shea et al. 1965; Smart et al. 2000). As the internal field we consider the IGRF geomagnetic model, which is a Gauss spherical harmonic model of the geomagnetic field, based on magnetic field measurements from geomagnetic stations, magnetometers and satellites (Langel 1987). As the external field model we use a semi-empirical Tsyganenko (1989) model which is based on a large number of satellite observations (Tsyganenko 1989). The model takes into 
account contributions from external magnetospheric sources: ring current, magnetotail current system, magnetopause currents and a large-scale system of field-aligned currents. The model takes into consideration seasonal and diurnal changes of the magnetospheric field as well as the geomagnetic activity level $K_{p}$. It provides seven different states of the magnetosphere corresponding to different levels of geomagnetic activity. It is driven only by the geomagnetic activity index $K_{p}$ and provides perfect balance between simplicity (Nevalainen et al. 2013) and realism (Kudela \& Usoskin 2004; Kudela et al. 2008). All computations of particle's transport in the geomagnetic field are performed with the MAGNETOCOSMICS code (Desorgher et al. 2005).

It is known that during major SEP events the configuration of the magnetosphere could be changed dramatically. Accordingly a magnetospheric model has been recently proposed (Tsyganenko \& Sitnov 2005). The influence of a storm-time geomagnetic field model (Tsyganenko \& Sitnov 2005), specifically on computation of neutron monitor asymptotic cones and the subsequent analysis of GLEs, is beyond the topic of this work and should be a subject of future study.

\subsection{Analysis of GLEs using data from the global neutron monitor network}

Details for the analysis of GLE events based on data from several NM stations are given in (Shea \& Smart 1982; Cramp et al. 1997; Bombardieri et al. 2006; Vashenyuk et al. 2006, 2008). Detailed description of the method used in this study is given by Mishev et al. (2014). The relative count rate increase of a given NM to a SEP event can be expressed as:

$$
\frac{\Delta N\left(P_{\text {cut }}\right)}{N}=\frac{\int_{P_{\text {cut }}}^{P_{\max }} J_{\text {sep }}(P) Y_{\mathrm{NM}}(P) G(\alpha(P)) \mathrm{d} P}{\int_{P_{\text {cut }}}^{\infty} J_{\mathrm{GCR}}(P, t) Y_{\mathrm{NM}}(P) \mathrm{d} P},
$$

where $J_{\text {sep }}(P)$ is the primary solar particles rigidity spectrum in the direction of a maximal flux, $J_{\mathrm{GCR}}(P, t)$ is the rigidity spectrum of GCR at given time $t, Y_{\mathrm{NM}}(P)$ is the NM yield function (Mishev et al. 2013), $G(\alpha(P))$ is the pitch angle distribution of SEPs, $N$ is the NM count rate due to GCR and $\Delta N\left(P_{\text {cut }}\right)$ is the count rate increase due to solar particles. In Eq. (4), $P_{\text {cut }}$ is the minimum rigidity cut-off of the station and $P_{\max }$ is the maximum rigidity considered in the model, assumed to be $20 \mathrm{GV}$. The fractional increase of the count rate of a NM station represents the ratio between the NM count rate due to SEP and that due to the GCR averaged over $2 \mathrm{~h}$ before the event's onset. For the GCR we apply the described above force field model and reconstructed solar modulation parameter according to Usoskin et al. (2011). A modified power law rigidity spectrum of SEP is assumed in the analysis similarly to Cramp et al. (1997); Bombardieri et al. (2006); Vashenyuk et al. (2008):

$$
J_{\text {sep }}(P)=J_{0} P^{-(\gamma+\delta \gamma(P-1))},
$$

where $J_{\text {sep }}$ is the particle flux arriving from the Sun along the pitch angle distribution (PAD) axis of symmetry defined by geographic coordinate angles $\Psi$ and $\Lambda, \gamma$ is the power-law spectral exponent at rigidity $P=1 \mathrm{GV}$ and $\delta \gamma$ is the rate of the spectrum steepening. The pitch angle distribution is assumed as a superposition of two Gaussians:

$$
G(\alpha(P))=\exp \left(-\alpha^{2} / \sigma_{1}^{2}\right)+B * \exp \left(-\left(\alpha-\alpha^{\prime}\right)^{2} / \sigma_{2}^{2}\right),
$$

where $\alpha$ is the pitch angle, $\sigma_{1}$ and $\sigma_{2}$ are parameters corresponding to the width of the pitch angle distribution and
$B$ is a parameter. At $B \rightarrow 0$, PAD becomes a Gaussian similar to Vashenyuk et al. (2006). The pitch angle is defined as the angle between the asymptotic direction and the axis of anisotropy. Therefore according to Eqs. (4)-(6), nine model parameters have to be determined: $J_{0}, \gamma, \delta \gamma, \Psi$ and $\Lambda, \alpha^{\prime}$, $\sigma_{1}, \sigma_{2}$ and $B$. This PAD allows to consider a bidirectional anisotropy similarly to Cramp et al. (1997), results from bouncing of particles inside a looped magnetic field structure (magnetic bottle). In the study presented here we obtained the best fit with a simple Gaussian for the PAD (see Table B.1).

\section{Application of the model for computation of the dose rate at various conditions}

Since the flux of GCR is isotropic, it is necessary to compute the rigidity cut-off at a given condition and to apply the described above model to assess the exposure due to GCR. During the GLE events, the exposure is a superposition of CR particles of galactic and solar origin. Since SEPs possess an essential anisotropic part, it is necessary to compute the asymptotic cones in the region of interest, in our case in a grid of $5^{\circ} \times 5^{\circ}$ in order to consider explicitly the anisotropy using the derived PAD.

\subsection{Exposure due to GCR and comparison of the model with reference data}

In order to compare the model with the reference data (Menzel 2010) we perform computations in various conditions. The ambient dose equivalent is computed at altitude of $35 \mathrm{kft}$ a.s.l. using the corresponding yield function. The estimated ambient dose equivalent as a function of the rigidity cut-off is presented in Figures 2a-2c. A good agreement is achieved, specifically in mid and high rigidity cut-off regions.

In general, our model computations demonstrate good agreement with reference data (see Figs. 2 and A.1). The modelled ambient dose equivalent tends to slightly overestimate the dose in the low rigidity cut-off region and underestimate it in high rigidity cut-off regions, similarly to Mertens et al. (2013). The slight underestimation of the reference data at the high level of the rigidity cut-off could be explained by the contribution of thunderstorm radiation, widely discussed in Dwyer et al. (2010) and Drozdov et al. (2013). The detailed study of the contribution of thunderstorm radiation within our model to exposure is a topic of a further work. The observed difference for 1998 and a marginal difference for 2000 in the region of low rigidity cut-off are mostly due to modulation effects and some specifics (cascade maximum) of atmospheric cascade development of heavier nuclei within their scaling to $\alpha$-particles (Mishev \& Velinov 2014). Accordingly, Figures $3 a-3 c$ show the computed effective dose rate as a function of the rigidity cut-off.

Some details are given in Appendix A. As one can see in Figure A.2, there is a general agreement between the model computations and reference data. The difference between the effective dose $E$ and the ambient dose equivalent $H^{*}(10)$ is shown in Figure A.3. One can see that the $H^{*}(10)$ is a conservative approach for the exposure in a low rigidity cut-off regions, while the effective dose is a conservative approach above some $5 \mathrm{GV}$ in accord with a recent study (Mertens et al. 2013). Moreover, our model 
A. Mishev and I. Usoskin: Numerical model for computation of effective dose at flight altitudes
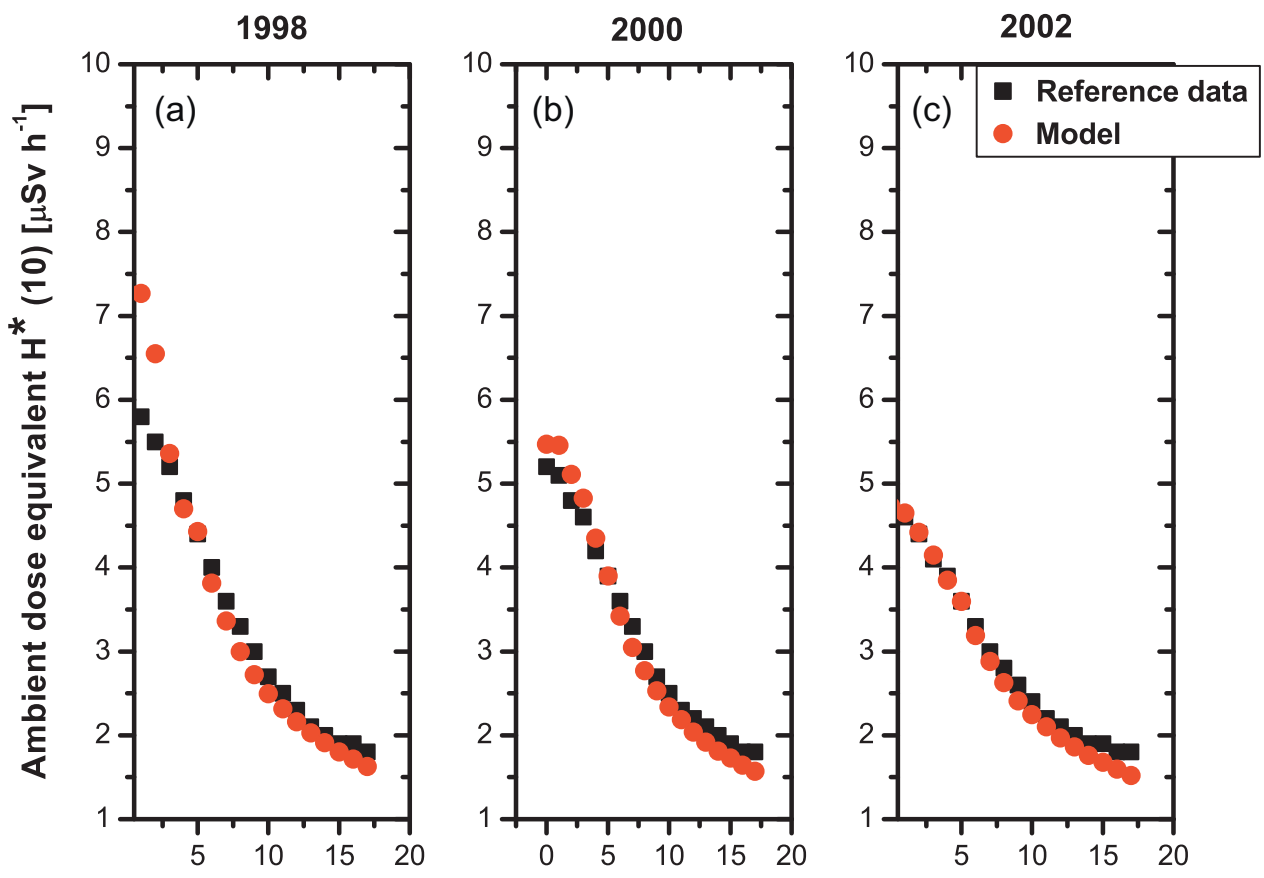

Rigidity cut-off [GV]

Fig. 2. Ambient dose equivalent $H^{*}(10)$ at the altitude of $35 \mathrm{kft}$ a.s.l. as a function of the rigidity cut-off computed at various conditions, compared with reference data Menzel (2010). (a) Ambient dose equivalent $H^{*}(10)$ for January 1998. Modulation potential $427 \mathrm{MV}$, (b) ambient dose equivalent $H^{*}(10)$ for January 2000. Modulation potential $752 \mathrm{MV}$, (c) ambient dose equivalent $H^{*}(10)$ for January 2002. Modulation potential $977 \mathrm{MV}$.
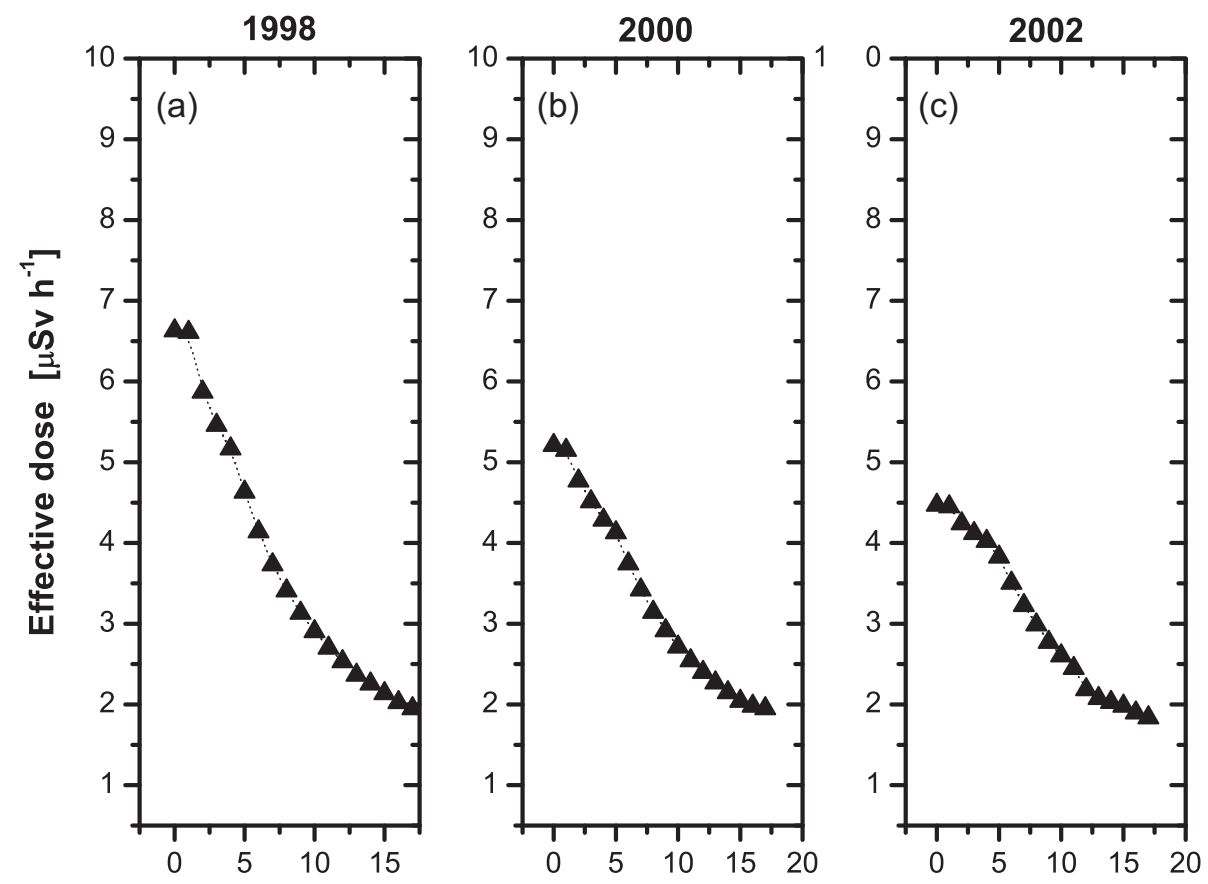

Rigidity cut-off [GV]

Fig. 3. Effective dose rate at the altitude of $35 \mathrm{kft}$ a.s.l. as a function of the rigidity cut-off computed at various conditions. (a) January 1998 , modulation potential 427 MV, (b) January 2000, modulation potential 752 MV, (c) January 2002, modulation potential 977 MV.

computations demonstrate better agreement with the reference data (Figs. A1 and A4) comparing to some recent works Mertens et al. (2013).

Our model also demonstrates good agreement with a recently proposed model for numerical computation of the radiation exposure from GCRs at aviation altitudes (Matthiä et al. 2014). Both models demonstrate good agreement with experimental/reference data, although the calculations slightly overestimate the measurements in the polar region, which are mostly due to modulation/GCR model effects. 
(a)

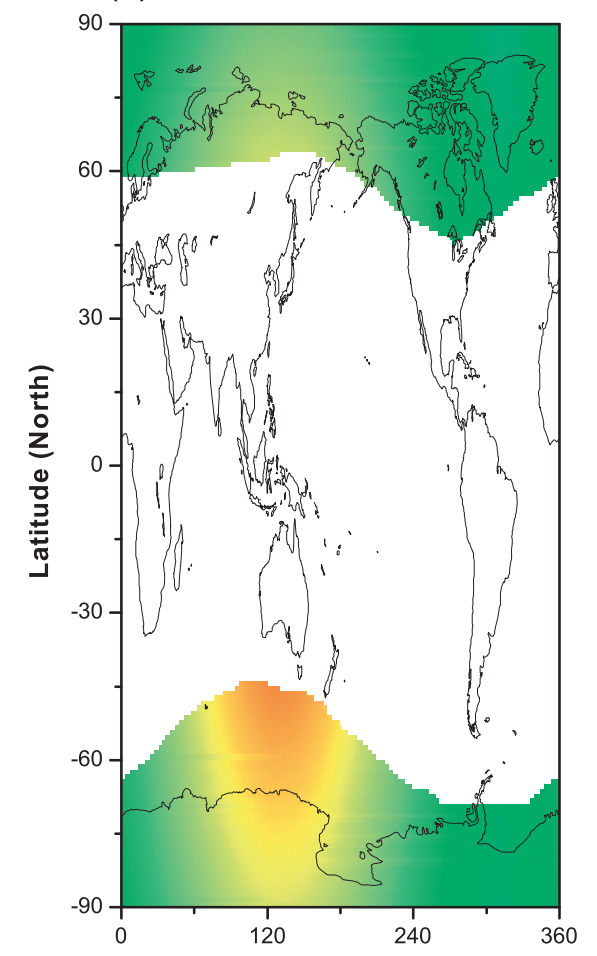

(b)

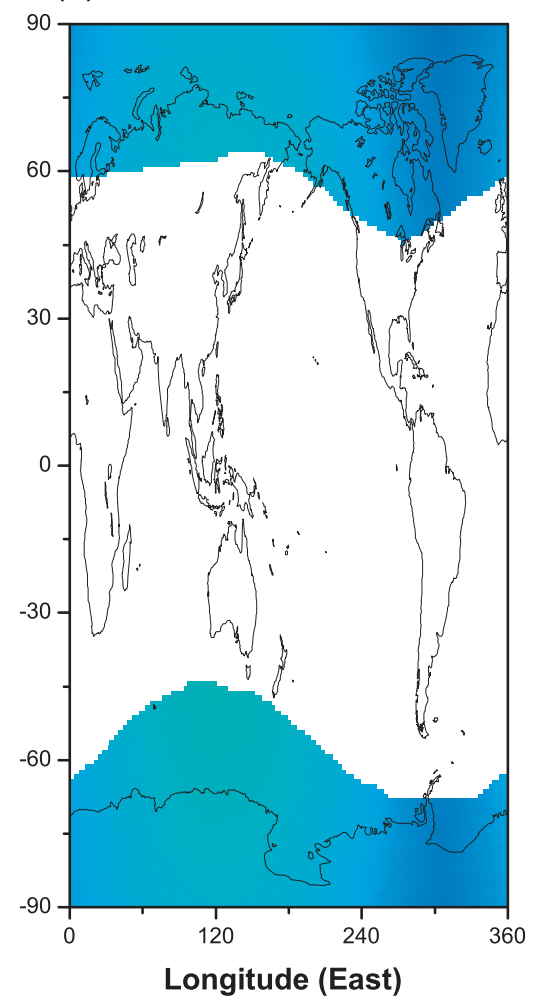

(c)

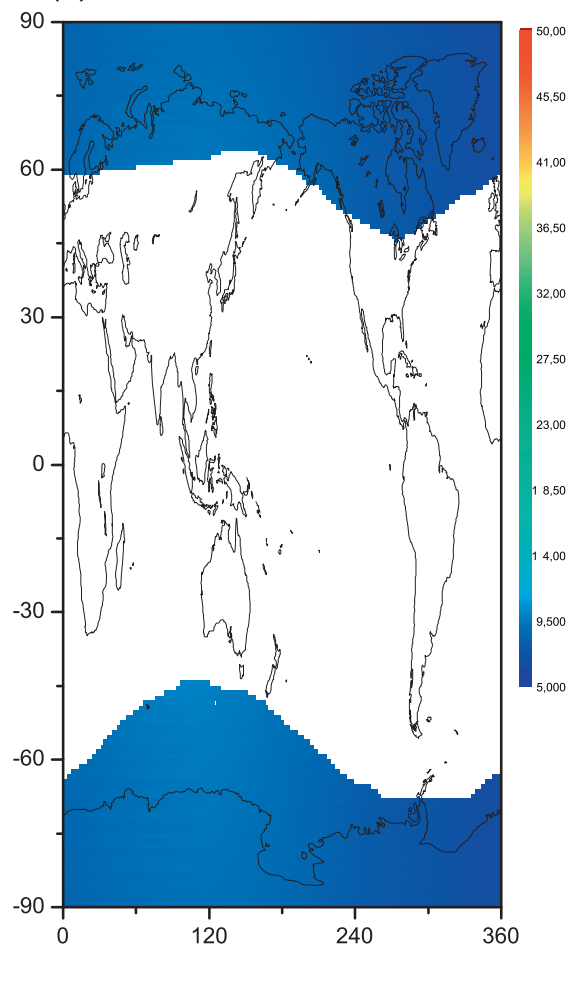

Fig. 4. The effective dose rate $\left(\mu \mathrm{Sv} \mathrm{h}{ }^{-1}\right)$ at the altitude of $35 \mathrm{kft}$ a.s.1. during the GLE 70 on 13 December 2006 in a region with $R_{c} \leq 1 \mathrm{GV}$. (a) initial phase of the event, (b) main phase of the event, (c) late phase of the event.

\subsection{Effective dose rate computed during GLE 70 on 13 December 2006}

The event of 13 December 2006 occurred during the decline phase of solar cycle 23 . The event was characterized by a large anisotropy in its initial phase. It has been well studied in the sense of exposure, specifically at flight altitudes (Beck 2009; Bütikofer et al. 2009; Matthiä et al. 2009). We derive the spectral and angular characteristics of SEPs using NM data as described above. The computed asymptotic cones of the NMs used for the analysis, the direction of heliospheric magnetic field (IMF) derived from ACE satellite measurements at 03:00 UT, the derived apparent source position and lines of equal pitch angles relative to the derived anisotropy axis for $30^{\circ}, 60^{\circ}, 150^{\circ}$ and $120^{\circ}$ are shown in Figure B.1 of Appendix B. Accordingly, the estimated apparent source position throughout the event is shown in Figure B.2. The spectral and angular characteristics are presented in Figure B.3. Accordingly, Table B.1 summarizes the details.

Subsequently, the effective dose rate at altitude of $35 \mathrm{kft}$ a.s.l. was computed on the basis of the described above model and the computed yield function (Appendix A). Since the initial phase of the event was very anisotropic, taking into account the falling SEP spectrum, we estimated the effective dose rate in a region with $R_{c} \leq 1 \mathrm{GV}$, where the expected exposure is maximal. The computed effective dose rate at the flight altitude during the initial phase of GLE 70 on 13 December 2006 was about $40-50 \mu \mathrm{Sv} \mathrm{h}{ }^{-1}$ (Fig. 4a), which is in a very good agreement with previous estimations (Matthiä et al. 2009). The computed effective dose rate during the main and late phases of the event is considerably lower (Figs. $4 b$ and $4 c$ ).

It is apparent that the contribution of SEP to the exposure due to $\mathrm{CR}$ is important, specifically during the initial phase of
GLE 70. During the main and late phases of GLE 70 the contribution of SEPs to the exposure is slightly greater compared to the average due to GCR.

As demonstrated recently the computed effective dose rate at flight altitude during GLEs is model dependent, specifically by the derived SEP spectra, angular distribution and apparent source position (Bütikofer \& Flückiger 2013). In this connection, we compared the estimated effective dose rate at altitude of $35 \mathrm{kft}$ a.s.l. during GLE 70 assuming various SEP spectra (Vashenyuk et al. 2008). Figure 5a shows the relative difference of the computed effective dose rate during the initial phase of GLE 70 assuming our derived spectra (Table B.1) and spectra by Vashenyuk et al. (2008). Similarly, the relative difference for the main phase is presented in Figure $5 \mathrm{~b}$.

One can see that the relative difference does not exceed $\sim 20 \%$, which is in very good agreement with the results of Bütikofer \& Flückiger (2013). During the initial phase of the event this difference is mostly due to the difference in the apparent source position determination, rather than the derived SEP spectra. The dramatic change of the observed difference in anti-sun direction is due to the point like PAD of SEPs during the initial phase of the event (Fig. B.3 and Table B.1). During the main and late phases of the event the derived by us SEP spectra lead to a more conservative approach of the estimated effective dose (Fig. 5b).

\section{Discussion}

According to the common definition, space weather refers to the dynamic, variable conditions on the Sun, solar wind and Earth's magnetosphere and ionosphere, that can compromise the performance and reliability of spacecraft and ground-based 
(a)

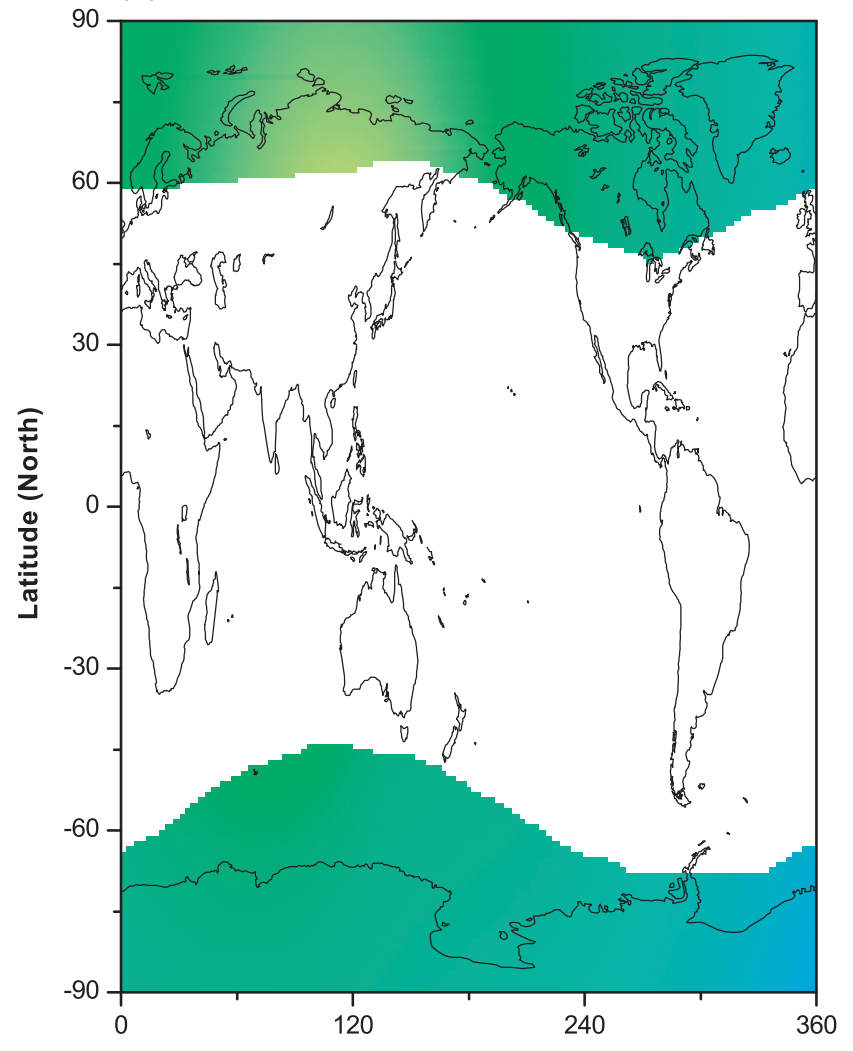

(b)

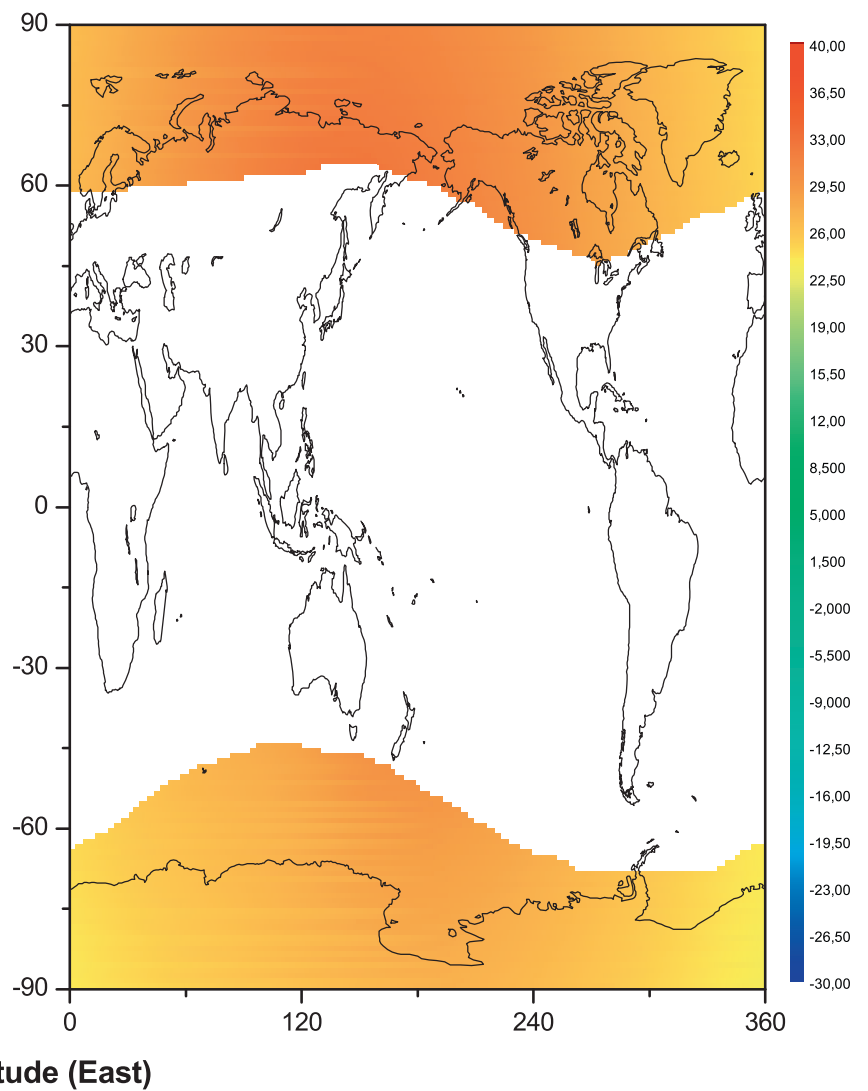

Fig. 5. The relative difference in $\%$ of the effective dose rate at the altitude of $35 \mathrm{kft}$ a.s.1. during the GLE 70 on 13 December 2006 assuming different spectral and angular characteristics of SEPs. (a) initial phase of the event, (b) main phase of the event.

systems and can endanger human life or health (Baker 1998; Lilensten \& Belehaki 2009; Lilensten \& Bornarel 2009). An important feature of space weather is the assessment of aircrew exposure due to CR, specifically during GLEs. At present there is no evidence of any immediate threat on human health from SEPs, and the biological risk of radiation doses accumulated by aircrew is still a matter of scientific debate (Sigurdson \& Ron 2004; Ballarini et al. 2007; Hammer et al. 2009; Pukkala et al. 2012; Dos Santos Silva et al. 2013). In addition, a recent survey of the exposure due to CRs demonstrated that none exceeded the recommended level of $6 \mathrm{mSv} / \mathrm{y}$ and the majority of aircrew received around $3 \mathrm{mSv} / \mathrm{y}$ (Bennett et al. 2013a, 2013b). However, according to several studies discovering chromosome aberrations in aircrew members, the topic deserves further investigations (Bolzan et al. 2008; Yong et al. 2009) as well as additional verification (Wolf et al. 1999). Therefore, the development of new models as well as the improvement and validation of existing models for dose assessment, specifically during GLEs, is of a big importance.

Since the difference between effective dose and ambient dose equivalent is slightly above the intrinsic atmospheric cascade simulations, specifically in the lower energy range, the application of both of them for dose assessment at flight altitudes is quite reasonable. The ambient dose equivalent looks more conservative in a low rigidity cut-off, while effective dose at high rigidity cut-off. Therefore the application of ambient dose equivalent is more conservative in the case of exposure assessment during SEP events, because the expected radiation environment change is more important in polar and sub-polar regions. Although, the application of effective dose responds to regulations and it is fully applicable as it is carried out in the presented here work.

\section{Conclusions}

In this paper we describe a fully operational model for exposure assessment of aircrew based on newly computed yield functions for effective and/or ambient dose equivalent. The model represents a full chain analysis of CR measurements with NMs, from spectral and angular characteristics of SEPs evaluation to dose assessment.

1. The model is validated and compared with reference data.

2. New yield functions for effective and/or ambient dose equivalent are presented.

3. The effective dose rate during GLE 70 on 13 December is computed as an example of application of the model.

Acknowledgements. This work was supported by the Center of Excellence ReSoLVE (Project No. 272157) and the University of Oulu Finland. The authors are grateful to colleagues from Institute for Nuclear Research and Nuclear Energy, Bulgarian Academy of Sciences and International Atomic Energy Agency in Vienna for technical support and discussions. The editor and authors thank T. Karapetyan and A. Drozdov for their assistance in evaluating this paper. 


\section{References}

Agostinelli, S., J. Allison, and K. Amako. Geant4 - a simulation toolkit. Nucl. Instrum. Methods Phys. Res.: Sect. A, 506 (3), 250-303, 2003, DOI: 10.1016/S0168-9002(03)01368-8.

Al Anid, H., B. Lewis, L. Bennett, M. Takada, and M. Duldig. Aircrew radiation dose estimates during recent solar particle events and the effect of particle anisotropy. Radiat. Prot. Dosim., 158 (3), 355-367, 2014, DOI: 10.1093/rpd/nct234.

Aschwanden, M. GeV particle acceleration in solar flares and ground level enhancement (GLE) events. Space Sci. Rev., 171 (1-4), 3-21, 2012, DOI: 10.1007/s11214-011-9865-x.

Baker, D. What is space weather? Adv. Space Res., 22 (1), 7-16, 1998.

Ballarini, F., D. Alloni, A. Facoetti, A. Mairani, R. Nano, and A. Ottolenghi. Radiation risk estimation: modelling approaches for "targeted" and "non-targeted" effects. Adv. Space Res., 40 (9), 1392-1400, 2007, DOI: 10.1016/j.asr.2007.04.021.

Battistoni, G., S. Muraro, P. Sala, F. Cerutti, A. Ferrari, S. Roesler, A. Fasso, and J. Ranft. The FLUKA code: description and benchmarking. In: Proceedings of the Hadronic Shower Simulation Workshop 2006, 6-8 September 2006, M., Albrow and R. Raja Editors, AIP Conference, 896, 31-49, 2007.

Bazilevskaya, G.A., I.G. Usoskin, E. Flückiger, R. Harrison, L. Desorgher, et al. Cosmic ray induced ion production in the atmosphere. Space Sci. Rev., 137, 149-173, 2008,

DOI: $10.1007 / \mathrm{s} 11214-008-9339-\mathrm{y}$

Beck, P. Overview of research on aircraft crew dosimetry during the last solar cycle. Radiat. Prot. Dosim., 136 (4), 244-250, 2009, DOI: $10.1093 / \mathrm{rpd} / \mathrm{ncp} 158$.

Bennett, L., B. Lewis, B. Bennett, M. McCall, M. Bean, L. Dor, and I. Getley. Cosmic radiation exposure survey of an air force transport squadron. Radiat. Meas., 48 (1), 35-42, 2013a, DOI: $10.1016 /$ j.radmeas.2012.10.012.

Bennett, L., B. Lewis, B. Bennett, M. McCall, M. Bean, L. Dor, and I. Getley. A survey of the cosmic radiation exposure of Air Canada pilots during maximum galactic radiation conditions in 2009. Radiat. Meas., 49 (1), 103-108, 2013b,

DOI: 10.1016/j.radmeas.2012.12.004.

Bolzan, A., M. Bianchi, E. Gimenez, M. Flaque, and V. Ciancio. Analysis of spontaneous and bleomycin-induced chromosome damage in peripheral lymphocytes of long-haul aircrew members from Argentina. Mutation Research - Fundamental and Molecular Mechanisms of Mutagenesis, 639 (1-2), 64-79, 2008, DOI: 10.1016/j.mrfmmm.2007.11.003.

Bombardieri, D., M. Duldig, K. Michael, and J. Humble. Relativistic proton production during the 2000 July 14 solar event: the case for multiple source mechanisms. Astrophys. J., 644 (1), 565-574, 2006, DOI: 10.1086/501519.

Bostanjyan, N., A. Chilingarian, V. Eganov, and G. Karapetyan. On the production of highest energy solar protons at 20 January 2005. Adv. Space Res., 39 (9), 1456-1459, 2007, DOI: $10.1016 / \mathrm{j}$.asr.2007.03.024

Briesmeister, J. MCNP A general Monte Carlo Transport code (version 4B). Tech. Rep. LA 12625-M, Los Alamos National Laboratory, 1997.

Bütikofer, R., and E. Flückiger. Differences in published characteristics of GLE60 and their consequences on computed radiation dose rates along selected flight paths. J. Phys: Conf. Ser., 409 (1), 012166, 2013.

Bütikofer, R., E. Flückiger, L. Desorgher, M. Moser, and B. Pirard. The solar cosmic ray ground-level enhancements on 20 January 2005 and 13 December 2006. Adv. Space Res., 43 (4), 499-503, 2009, DOI: 10.1016/j.asr.2008.08.001.

Caballero-Lopez, R., and H. Moraal. Limitations of the force field equation to describe cosmic ray modulation. J. Geophys. Res., 109, A01101, 2004, DOI: 10.1029/2003JA010098.

Clem, J. Contribution of Obliquely incident particles to neutron monitor counting rate. J. Geophys. Res., 102, 919, 1997.
Cliver, E., S. Kahler, and D. Reames. Coronal shocks and solar energetic proton events. Astrophys. J., 605, 902-910, 2004, DOI: $10.1086 / 382651$.

Cooke, D., J. Humble, M. Shea, D. Smart, N. Lund, I. Rasmussen, B. Byrnak, P. Goret, and N. Petrou. On cosmic-ray cutoff terminology. IL Nuovo Cimento C, 14 (3), 213-234, 1991.

Cramp, J., M. Duldig, E. Flückiger, J. Humble, M. Shea, and D. Smart. The October 22, 1989, solar cosmic ray enhancement: an analysis of the anisotropy spectral characteristics. J. Geophys. Res., 102 (A11), 24237-24248, 1997.

Desorgher, L., E. Flückiger, M. Gurtner, M. Moser, and R. Bütikofer. A Geant 4 code for computing the interaction of cosmic rays with the Earth's atmosphere. Int. J. Mod. Phys. A, 20 (A11), 6802, 2005, DOI: 10.1142/S0217751X05030132.

Desorgher, L., K. Kudela, E. Flückiger, R. Bütikofer, M. Storini, and V. Kalegaev. Comparison of Earth's magnetospheric magnetic field models in the context of cosmic ray physics. Acta Geophys., 57 (1), 75-87, 2009, DOI: 10.2478/s11600-008-0065-3.

Dorman, L. Cosmic Rays in the Earth's Atmosphere Underground, Kluwer Academic Publishers, Dordrecht, ISBN 1-4020-2071-6, 2004.

Dos Santos Silva, I., B. De Stavola, C. Pizzi, A. Evans, and S. Evans. Cancer incidence in professional flight crew and air traffic control officers: disentangling the effect of occupational versus lifestyle exposures. International Journal of Cancer, 132 (2), 374-384, 2013, DOI: 10.1002/ijc.27612.

Drozdov, A., A. Grigoriev, and Y. Malyshkin. Assessment of thunderstorm neutron radiation environment at altitudes of aviation flights. J. Geophys. Res. [Space Phys.], 118 (2), 947-955, 2013, DOI: 10.1029/2012JA018302.

Dwyer, J.R., D.M. Smith, M.A. Uman, Z. Saleh, B. Grefenstette, B. Hazelton, and H.K. Rassoul. Estimation of the fluence of highenergy electron bursts produced by thunderclouds and the resulting radiation doses received in aircraft. J. Geophys. Res. [Atmos.], 115 (D9), 2010, DOI: 10.1029/2009JD012039.

EURATOM. Council Directive 96/29/EURATOM of 13 May 1996 laying down basic safety standards for protection of the health of workers and the general public against the dangers arising from ionising radiation. Official Journal of the European Communities, 39 (L159), 1996.

Fasso, A., A. Ferrari, J. Ranft, and P. Sala. FLUKA: a multi-particle transport code. SLAC-R-773 2005-10, CERN, CERN, Geneva, 2005.

Ferrari, A., M. Pelliccioni, and T. Rancati. Calculation of the radiation environment caused by galactic cosmic rays for determining air crew exposure. Radiat. Prot. Dosim., 93 (2), 101-114, 2001

Forbush, S. Cosmic-ray intensity variations during two solar cycles. J. Geophys. Res., 63 (4), 651-669, 1958.

Gaisser, T.K., and T. Stanev. Cosmic rays. In: K. N. et al., ed. Review of Particle Physics, 269-275, J. Phys. G, 37, 269-275, 2010.

Gleeson, L., and W. Axford. Solar modulation of galactic cosmic rays. Astrophys. J., 154, 1011-1026, 1968

Hammer, G., M. Blettner, and H. Zeeb. Epidemiological studies of cancer in aircrew. Radiat. Prot. Dosim., 136 (4), 232-239, 2009, DOI: $10.1093 / \mathrm{rpd} / \mathrm{ncp} 125$

ICRP. ICRP Publication 60: 1990 recommendations of the international commission on radiological protection. Ann. ICRP, 21 (1-3), 1991.

ICRP. ICRP Publication 103: the 2007 recommendations of the international commission on radiological protection. Ann. ICRP, 37 (2-4), 2007.

ICRP. ICRP Publication 110: adult reference computational phantoms. Ann. ICRP, 39 (2), 2009.

Iwase, H., K. Niita, and T. Nakamura. Development of generalpurpose particle and heavy ion transport Monte Carlo code. J. Nucl. Sci. Technol., 39 (11), 1142-1151, 2002. 
Kawrakow, I. Electron impact ionization cross sections for EGSnrc. Med. Phys., 29, 1230, 2001.

Kovaltsov, G., A. Mishev, and I. Usoskinc. A new model of cosmogenic production of radiocarbon $14 C$ in the atmosphere. Earth Planet. Sci. Lett., 337, 114-120, 2012, DOI: 10.1016/j.epsl.2012.05.036.

Kudela, K., R. Bučik, and P. Bobik. On transmissivity of low energy cosmic rays in disturbed magnetosphere. Adv. Space Res., 42 (7), 1300-1306, 2008, DOI: 10.1016/j.asr.2007.09.033.

Kudela, K., and I. Usoskin. On magnetospheric transmissivity of cosmic rays. Czech. J. Phys., 54 (2), 239-254, 2004, DOI: 10.1023/B:CJOP.0000014405.61950.e5.

Langel, R. Main Field in Geomagnetism. In: Geomagnetism, chap. 1, 249-512, J.A. Jacobs Academic Press, London, 1987.

Lewis, B., L. Bennett, A. Green, A. Butler, M. Desormeaux, F. Kitching, M. McCall, B. Ellaschuk, and M. Pierre. Aircrew dosimetry using the Predictive Code for Aircrew Radiation Exposure (PCAIRE). Radiat. Prot. Dosim., 116 (1-4), 320-326, 2005, DOI: $10.1093 / \mathrm{rpd} / \mathrm{nci} 024$.

Lilensten, J., and A. Belehaki. Developing the scientific basis for monitoring, modelling and predicting space weather. Acta Geophys., 57 (1), 1-14, 2009, DOI: 10.2478/s11600-008-0081-3.

Lilensten, L., and J. Bornarel. Space Weather, Environment and Societies, Springer, Dordrecht, ISBN 978-1-4020-4332-1, 2009.

Matthiä, D., B. Heber, G. Reitz, L. Sihver, T. Berger, and M. Meier. The ground level event 70 on December 13th, 2006 and related effective doses at aviation altitudes. Radiat. Prot. Dosim., 136 (4), 304-310, 2009, DOI: 10.1093/rpd/ncp141.

Matthiä, D., M. Meier, and G. Reitz. Numerical calculation of the radiation exposure from galactic cosmic rays at aviation altitudes with the PANDOCA core model. Space Weather, 12 (3), 161-171, 2014, DOI: 10.1002/2013SW001022.

Matthiä, D., L. Sihver, and M. Meier. Monte-Carlo calculations of particle fluences and neutron effective dose rates in the atmosphere. Radiat. Prot. Dosim., 131 (2), 222-228, 2008, DOI: $10.1093 / \mathrm{rpd} / \mathrm{ncn} 130$.

Mavromichalaki, H., A. Papaioannou, C. Plainaki, C. Sarlanis, G. Souvatzoglou, et al. Applications and usage of the real-time Neutron Monitor Database. Adv. Space Res., 47, 2210-2222, 2011, DOI: 10.1016/j.asr.2010.02.019.

McCracken, K., V. Rao, B. Fowler, M. Shea, and D. Smart. Cosmic ray tables (asymptotic directions, etc.). In: Annals of the IQSY, chap. 1, 198-214, MIT Press, Cambridge, MA, USA, 1968.

McCracken, K., V. Rao, and M. Shea. The trajectories of cosmic rays in a high degree simulation of the geomagnetic field. Technical Report 77, Massachusetts Institute of Technology, Cambridge, MA, USA, 1962

Meier, M., M. Hubiak, D. Matthiä, M. Wirtz, and G. Reitz. Dosimetry at aviation altitudes (2006-2008). Radiat. Prot. Dosim., 136 (4), 1-35, 2009, DOI: 10.1093/rpd/ncp142.

Menzel, H. The international commission on radiation units and measurements. Journal of the ICRU, 10 (2), 1-35, 2010.

Mertens, C., M. Meier, S. Brown, R. Norman, and X. Xu. NAIRAS aircraft radiation model development, dose climatology, and initial validation. Space Weather, 11 (10), 603-635, 2013, DOI: $10.1002 /$ swe. 20100

Mishev, A. Computation of radiation environment during ground level enhancements 65, 69 and 70 at equatorial region and flight altitudes. Adv. Space Res., 54 (3), 528-535, 2014, DOI: $10.1016 /$ j.asr.2013.10.010.

Mishev, A., F. Adibpour, I. Usoskin, and E. Felsberger. Computation of dose rate at flight altitudes during ground level enhancements no. 69, 70 and 71. Adv. Space Res., 55 (1), 354-362, 2015, DOI: $10.1016 /$ j.asr.2014.06.020.

Mishev, A., and E. Hristova. Recent gamma background measurements at high mountain altitude. J. Environ. Radioact., 113, 77-82, 2012, DOI: 10.1016/j.jenvrad.2012.04.017.

Mishev, A., L. Kocharov, and I. Usoskin. Analysis of the ground level enhancement on 17 May 2012 using data from the global neutron monitor network. J. Geophys. Res., 119, 670-679, 2014, DOI: $10.1002 / 2013$ JA019253.

Mishev, A., and I. Usoskin. Computations of cosmic ray propagation in the Earth's atmosphere, towards a GLE analysis. J. Phys: Conf. Ser., 409, 012152, 2013.

Mishev, A., I. Usoskin, and G. Kovaltsov. Neutron monitor yield function: new improved computations. J. Geophys. Res., 118, 2783-2788, 2013, DOI: 10.1002/jgra.50325.

Mishev, A., and P. Velinov. Influence of hadron and atmospheric models on computation of cosmic ray ionization in the atmosphere-Extension to heavy nuclei. J. Atmos. Sol. Terr. Phys., 120, 111-120, 2014, DOI: 10.1016/j.jastp. 2014.09.007.

Mishev, A., and P.I. Velinov. Normalized ionization yield function for various nuclei obtained with full Monte Carlo simulations. Adv. Space Res., 48 (1), 19-24, 2011, DOI: 10.1016/j.asr.2011.02.008.

Nevalainen, J., I. Usoskin, and A. Mishev. Eccentric dipole approximation of the geomagnetic field: application to cosmic ray computations. Adv. Space Res., 52 (1), 22-29, 2013, DOI: 10.1016/j.asr.2013.02.020.

O'Brien, K., W. Friedberg, H. Sauer, and D. Smart. Atmospheric cosmic rays and solar energetic particles at aircraft altitudes. Environ. Int., 22 (Suppl. 1), S9-S44, 1997.

Pelliccioni, M. Overview of fluence-to-effective dose and fluenceto-ambient dose equivalent conversion coefficients for high energy radiation calculated using the FLUKA Code. Radiat. Prot. Dosim., 88 (4), 279-297, 2000.

Petoussi-Henss, N., W. Bolch, K. Eckerman, A. Endo, N. Hertel, J. Hunt, M. Pelliccioni, H. Schlattl, and M. Zankl. Conversion coefficients for radiological protection quantities for external radiation exposures. Ann. ICRP, 40 (2-5), 1-257, 2010.

Picone, J., A. Hedin, D. Drob, and A. Aikin. NRLMSISE-00 empirical model of the atmosphere: statistical comparisons and scientific issues. J. Geophys. Res., 107 (A12), 2002.

Pukkala, E., M. Helminen, T. Haldorsen, N. Hammar, K. Kojo, A. Linnersj, V. Rafnsson, H. Tulinius, U. Tveten, and A. Auvinen. Cancer incidence among Nordic airline cabin crew. International Journal of Cancer, 131 (12), 2886-2897, 2012.

DOI: $10.1002 / \mathrm{ijc} .27551$.

Reames, D. Particle acceleration at the Sun and in the heliosphere. Space Sci. Rev., 90 (3-4), 13-491, 1999.

Roesler, S., W. Heinrich, and H. Schraube. Monte Carlo calculation of the radiation field at aircraft altitudes. Radiat. Prot. Dosim., 98 (4), 367-388, 2002.

Sato, T., A. Endo, M. Zankl, N. Petoussi-Henss, H. Yasuda, and K. Niita. Fluence-to-dose conversion coefficients for aircrew dosimetry based on the new ICRP Recommendations. Progress in Nuclear Science and Technology, 1, 134-137, 2011.

Sato, T., H. Yasuda, K. Niita, A. Endo, and L. Sihver. Development of PARMA: PHITS-based analytical radiation model in the atmosphere. Radiat. Res., 170, 244-259, 2008, DOI: $10.1667 /$ RR1094.1.

Schraube, H., G. Leuthold, W. Heinrich, S. Roesler, and D. Combecher. European program package for the calculation of aviation route doses, version 3.0. Tech. Rep. D-85758, National Research Center for Environment and Health Institute of Radiation Protection, Neuherberg, Germany, 2000.

Shea, M., and D. Smart. Possible evidence for a rigidity-dependent release of relativistic protons from the solar corona. Space Sci. Rev., 32, 251-271, 1982.

Shea, M., and D. Smart. A summary of major solar proton events. Sol. Phys., 127, 297-320, 1990.

Shea, M., and D. Smart. Cosmic ray implications for human health. Space Sci. Rev., 93 (1-2), 187-205, 2000, DOI: $10.1023 / \mathrm{A}: 1026544528473$.

Shea, M., and D. Smart. Space weather and the ground-level solar proton events of the 23rd solar cycle. Space Sci. Rev., 171, 161-188, 2012, DOI: 10.1007/s11214-012-9923-z. 
Shea, M., D. Smart, and K. McCracken. A study of vertical cut off rigidities using sixth degree simulations of the geomagnetic field. J. Geophys. Res., 70, 4117-4130, 1965.

Sigurdson, A., and E. Ron. Cosmic radiation exposure and cancer risk among flight crew. Cancer Investigation, 22 (5), 743-761, 2004, DOI: 10.1081/CNV-200032767.

Smart, D., M. Shea, and E. Flückiger. Magnetospheric models and trajectory computations. Space Sci. Rev., 93 (1), 305-333, 2000.

Spurny, F., I. Votockova, and J. Bottollier-Depois. Geographical influence on the radiation exposure of an aircrew on board a subsonic aircraft. Radioprotection, 31 (2), 275-280, 1996.

Spurny, F., T. Dachev, and K. Kudela. Increase of onboard aircraft exposure level during a solar flare. Nuclear Energy Safety, 10 (48), 396-400, 2002.

Tsyganenko, N. A magnetospheric magnetic field model with a warped tail current sheet. Planet. Space Sci., 37 (1), 5-20, 1989.

Tsyganenko, N., and M. Sitnov. Modeling the dynamics of the inner magnetosphere during strong geomagnetic storms. J. Geophys. Res. [Space Phys.], 110 (A3), 2005, DOI: $10.1029 / 2004 J A 010798$.

Usoskin, I., K. Alanko-Huotari, G. Kovaltsov, and K. Mursula. Heliospheric modulation of cosmic rays: monthly reconstruction for 1951-2004. J. Geophys. Res., 110 (A12108), 2005, DOI: 10.1029/2005JA01125.

Usoskin, I., G. Bazilevskaya, and G.A. Kovaltsov. Solar modulation parameter for cosmic rays since 1936 reconstructed from groundbased neutron monitors and ionization chambers. J. Geophys Res., 116 (A02), 104, 2011, DOI: 10.1029/2010JA016105.
Usoskin, I., and G. Kovaltsov. Cosmic ray induced ionization in the atmosphere: full modeling and practical applications. J. Geophys. Res., 111 (D21206), 2006, DOI: 10.1029/2006JD007150.

Usoskin, I.G., L. Desorgher, P. Velinov, M. Storini, E. Flückiger, R. Bütikofer, and G. Kovaltsov. Ionization of the Earth's atmosphere by solar and galactic cosmic rays. Acta Geophys., 57 (1), 88-101, 2009, DOI: 10.2478/s11600-008-0019-9.

Vainio, R., L. Desorgher, D. Heynderickx, M. Storini, E. Flückiger, et al. Dynamics of the Earth's particle radiation environment. Space Sci. Rev., 147 (3-4), 187-231, 2009 DOI: $10.1007 / \mathrm{s} 11214-009-9496-7$.

Vashenyuk, E., Y. Balabin, B. Gvozdevsky, and L. Schur. Characteristics of relativistic solar cosmic rays during the event of December 13, 2006. Geomag. Aeron., 48 (2), 149-153, 2008, DOI: $10.1007 / \mathrm{s} 11478-008-2003-6$.

Vashenyuk, E., Y. Balabin, J. Perez-Peraza, A. Gallegos-Cruz, and L. Miroshnichenko. Some features of the sources of relativistic particles at the Sun in the solar cycles 21-23. Adv. Space Res., 38 (3), 411-417, 2006, DOI: 10.1016/j.asr.2005.05.012.

Waters, L., G. McKinney, J. Durkee, M. Fensin, J. Hendricks, M. James, R. Johns, and D. Pelowitz. The MCNPX Monte Carlo radiation transport code. AIP Conference Proceedings, 896 (1), 81-90, 2007, DOI: 10.1063/1.2720459.

Wolf, G., G. Obe, and L. Bergau. Cytogenetic investigations in flight personnel. Radiat. Prot. Dosim., 86 (4), 275-278, 1999.

Yong, L., A. Sigurdson, E. Ward, M. Waters, E. Whelan, M. Petersen, P. Bhatti, M. Ramsey, E. Ron, and J. Tucker. Increased frequency of chromosome translocations in airline pilots with long-term flying experience. Occupational and Environmental Medicine, 66 (1), 56-62, 2009, DOI: 10.1136/oem.2008.038901.

Cite this article as: Mishev A \& Usoskin I. Numerical model for computation of effective and ambient dose equivalent at flight altitudes. $J$. Space Weather Space Clim., 5, A10, 2015, DOI: 10.1051/swsc/2015011. 
A. Mishev and I. Usoskin: Numerical model for computation of effective dose at flight altitudes

\section{Appendix A. Effective dose and ambient dose equivalent tables}

Table A.1 presents the effective dose yield function $Y\left[\mathrm{~Sv} \mathrm{~cm}^{2}\right.$ sr nucleon $\left.{ }^{-1}\right]$ for primary protons and $\alpha$-particles with isotropic incidence. The effective dose yield function is computed at the altitudes of $35 \mathrm{kft}$ a.s.l. (typical commercial flights $\approx 10.5 \mathrm{~km}$ a.s.1.) and $50 \mathrm{kft}$ a.s.l. (supersonic flights $\approx 15 \mathrm{~km}$ a.s.l.). Accordingly, the ambient dose equivalent $H^{*}(10)$ yield function $Y^{*}\left[\mathrm{~Sv} \mathrm{~cm}^{2} \mathrm{sr}\right.$ nucleon $^{-1}$ ] for primary protons and $\alpha$-particles at the altitude of $35 \mathrm{kft}$ a.s.l. is given in Table A.2.

Table A.1. Effective dose yield function $Y\left[\mathrm{~Sv} \mathrm{~cm}^{2} \mathrm{sr}_{\text {nucleon }}{ }^{-1}\right]$ for primary proton and $\alpha$-particles at the altitudes of $35 \mathrm{kft}$ and $50 \mathrm{kft}$ a.s.l.

\begin{tabular}{lcccc}
\hline \hline E $[\mathrm{GeV} /$ nucleon] & \multicolumn{2}{c}{$35 \mathrm{kft}$ a.s.1. } & \multicolumn{2}{c}{$50 \mathrm{kft}$ a.s.1. } \\
\cline { 2 - 3 } & Proton & $\alpha$-particle & Proton & $\alpha$-particle \\
\hline 0.5 & $3.81 \times 10^{-12}$ & $2.51 \times 10^{-12}$ & $5.4 \times 10^{-12}$ \\
1 & $4.41 \times 10^{-11}$ & $3.47 \times 10^{-11}$ & $1.08 \times 10^{-10}$ & $9.26 \times 10^{-11}$ \\
3 & $1.61 \times 10^{-10}$ & $8.72 \times 10^{-11}$ & $2.42 \times 10^{-10}$ & $2.07 \times 10^{-10}$ \\
5 & $2.75 \times 10^{-10}$ & $2.19 \times 10^{-10}$ & $4.89 \times 10^{-10}$ & $4.06 \times 10^{-10}$ \\
10 & $5.21 \times 10^{-10}$ & $4.38 \times 10^{-10}$ & $8.97 \times 10^{-10}$ & $7.40 \times 10^{-10}$ \\
50 & $2.21 \times 10^{-9}$ & $2.21 \times 10^{-9}$ & $3.72 \times 10^{-9}$ & $3.72 \times 10^{-9}$ \\
100 & $4.5 \times 10^{-9}$ & $4.5 \times 10^{-9}$ & $7.13 \times 10^{-9}$ & $7.13 \times 10^{-9}$ \\
500 & $2.48 \times 10^{-8}$ & $2.48 \times 10^{-8}$ & $3.13 \times 10^{-8}$ & $3.13 \times 10^{-8}$ \\
1000 & $5.37 \times 10^{-8}$ & $5.37 \times 10^{-8}$ & $6.03 \times 10^{-8}$ & $6.03 \times 10^{-8}$ \\
\hline
\end{tabular}

Table A.2. Ambient dose equivalent $H^{*}(10)$ yield function $Y^{*}\left[\mathrm{~Sv} \mathrm{~cm}^{2}\right.$ sr nucleon $\left.{ }^{-1}\right]$ for primary protons and $\alpha$-particles at the altitude of $35 \mathrm{kft}$ a.s.l.

\begin{tabular}{lcc}
\hline \hline E [GeV/nucleon] & Proton & $\alpha$-particle \\
\hline 0.5 & $8.67 \times 10^{-12}$ & $3.96 \times 10^{-12}$ \\
1 & $4.75 \times 10^{-11}$ & $3.57 \times 10^{-11}$ \\
3 & $1.63 \times 10^{-10}$ & $1.28 \times 10^{-10}$ \\
5 & $3.75 \times 10^{-10}$ & $2.64 \times 10^{-10}$ \\
10 & $4.82 \times 10^{-10}$ & $4.22 \times 10^{-10}$ \\
50 & $2.03 \times 10^{-9}$ & $2.03 \times 10^{-9}$ \\
100 & $3.76 \times 10^{-9}$ & $3.76 \times 10^{-9}$ \\
500 & $1.37 \times 10^{-8}$ & $1.37 \times 10^{-8}$ \\
1000 & $2.8 \times 10^{-8}$ & $2.8 \times 10^{-8}$ \\
\hline
\end{tabular}

Table A.3. Effective dose yield function $Y\left[\mathrm{~Sv} \mathrm{~cm}^{2} \mathrm{sr}\right.$ nucleon $\left.{ }^{-1}\right]$ for primary protons with various incidence at the altitude of $35 \mathrm{kft}$ a.s.1.

\begin{tabular}{lcccr}
\hline \hline E [GeV/nucleon] & $0^{\circ}$ & $15^{\circ}$ & $30^{\circ}$ \\
\hline 0.5 & $3.95 \times 10^{-12}$ & $3.87 \times 10^{-12}$ & $3.01 \times 10^{-12}$ & $45^{\circ}$ \\
1 & $4.55 \times 10^{-11}$ & $4.51 \times 10^{-11}$ & $3.64 \times 10^{-11}$ & $2.17 \times 10^{-12}$ \\
3 & $1.88 \times 10^{-10}$ & $1.75 \times 10^{-10}$ & $1.49 \times 10^{-10}$ & $1.25 \times 10^{-10}$ \\
5 & $3.2 \times 10^{-10}$ & $2.95 \times 10^{-10}$ & $2.57 \times 10^{-10}$ & $2.34 \times 10^{-10}$ \\
7 & $4.32 \times 10^{-10}$ & $3.99 \times 10^{-10}$ & $3.56 \times 10^{-10}$ & $3.37 \times 10^{-10}$ \\
10 & $5.61 \times 10^{-10}$ & $5.28 \times 10^{-10}$ & $4.78 \times 10^{-10}$ & $4.45 \times 10^{-10}$ \\
15 & $8.43 \times 10^{-10}$ & $8.03 \times 10^{-10}$ & $7.05 \times 10^{-10}$ & $6.87 \times 10^{-10}$ \\
20 & $1.12 \times 10^{-9}$ & $9.81 \times 10^{-10}$ & $9.34 \times 10^{-10}$ & $8.67 \times 10^{-10}$ \\
\hline
\end{tabular}



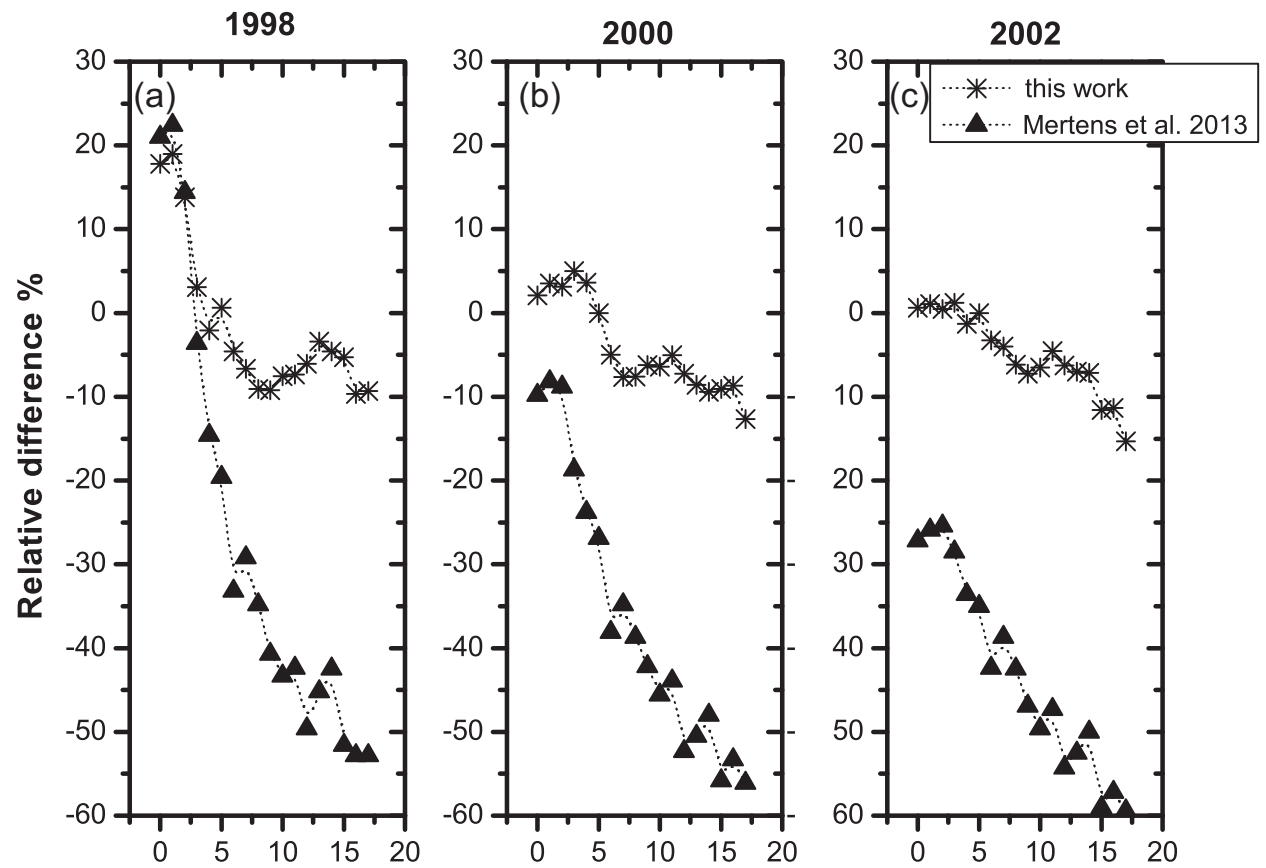

Rigidity cut-off [GV]

Fig. A.1. Relative difference between computed ambient dose equivalent $H^{*}(10)$ at the altitude of $35 \mathrm{kft}$ a.s.l. and the reference data (Menzel 2010). (a) January 1998, modulation potential 427 MV, (b) January 2000, modulation potential 752 MV, (c) January 2002, modulation potential 977 MV. The modulation potential is according to Usoskin et al. (2011).
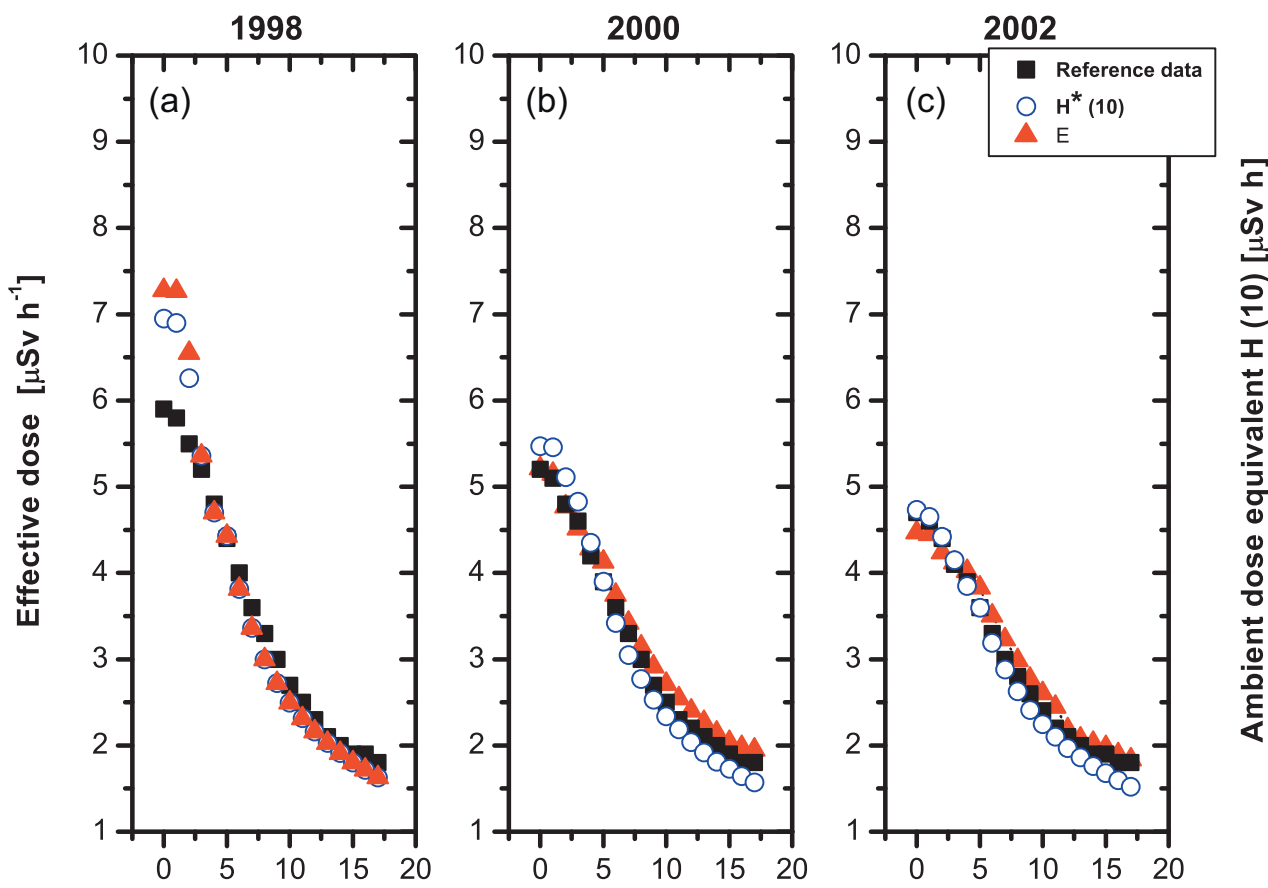

Rigidity cut-off [GV]

Fig. A.2. Computed effective dose $E$, ambient dose equivalent $H^{*}(10)$ and reference data (Menzel 2010) at the altitude of $35 \mathrm{kft}$ a.s.1. (a) January 1998, (b) January 2000, (c) January 2002. 
A. Mishev and I. Usoskin: Numerical model for computation of effective dose at flight altitudes
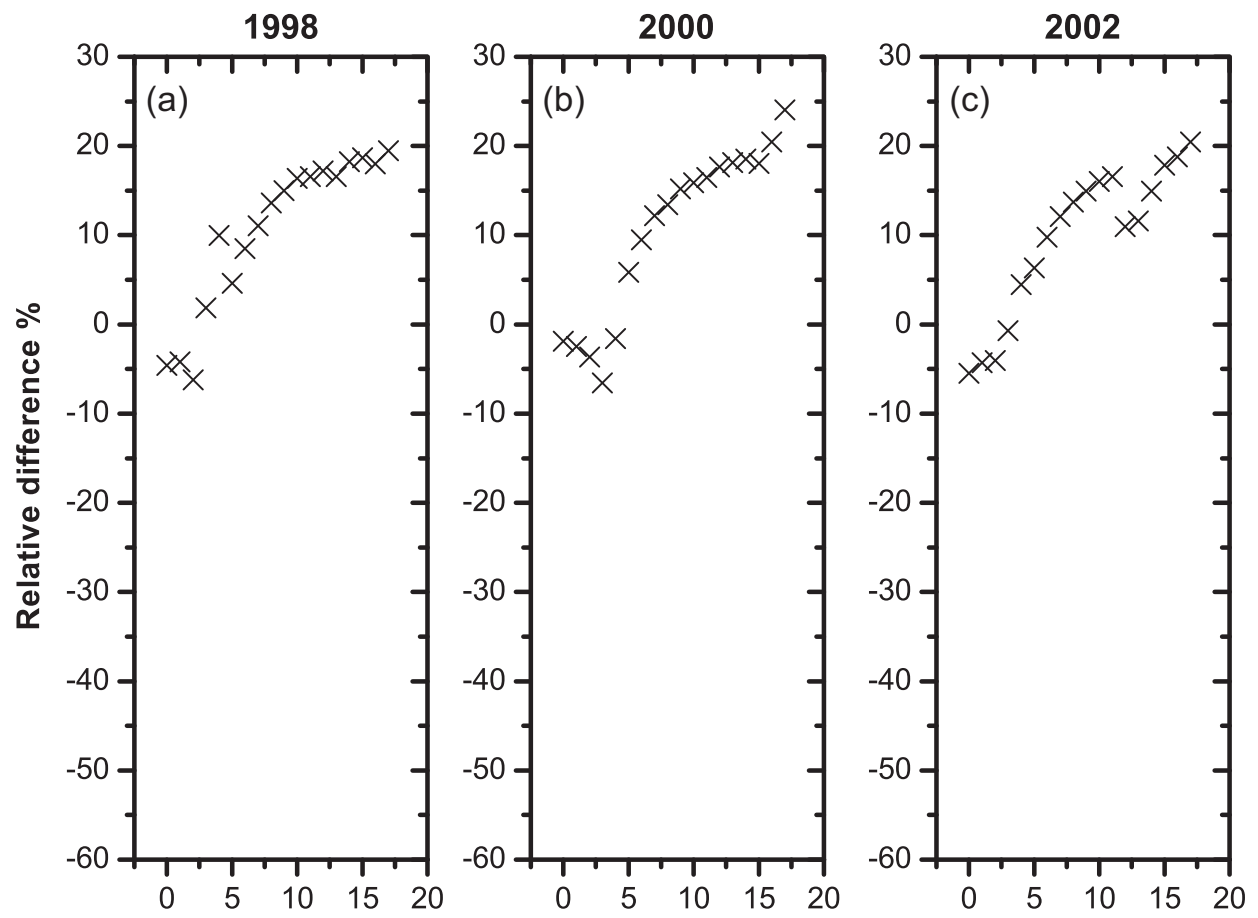

Rigidity cut-off [GV]

Fig. A.3. Relative difference between computed effective dose $E$ and ambient dose equivalent $H^{*}(10)$ at the altitude of 35 kft a.s.l. (a) January 1998, (b) January 2000, (c) January 2002.
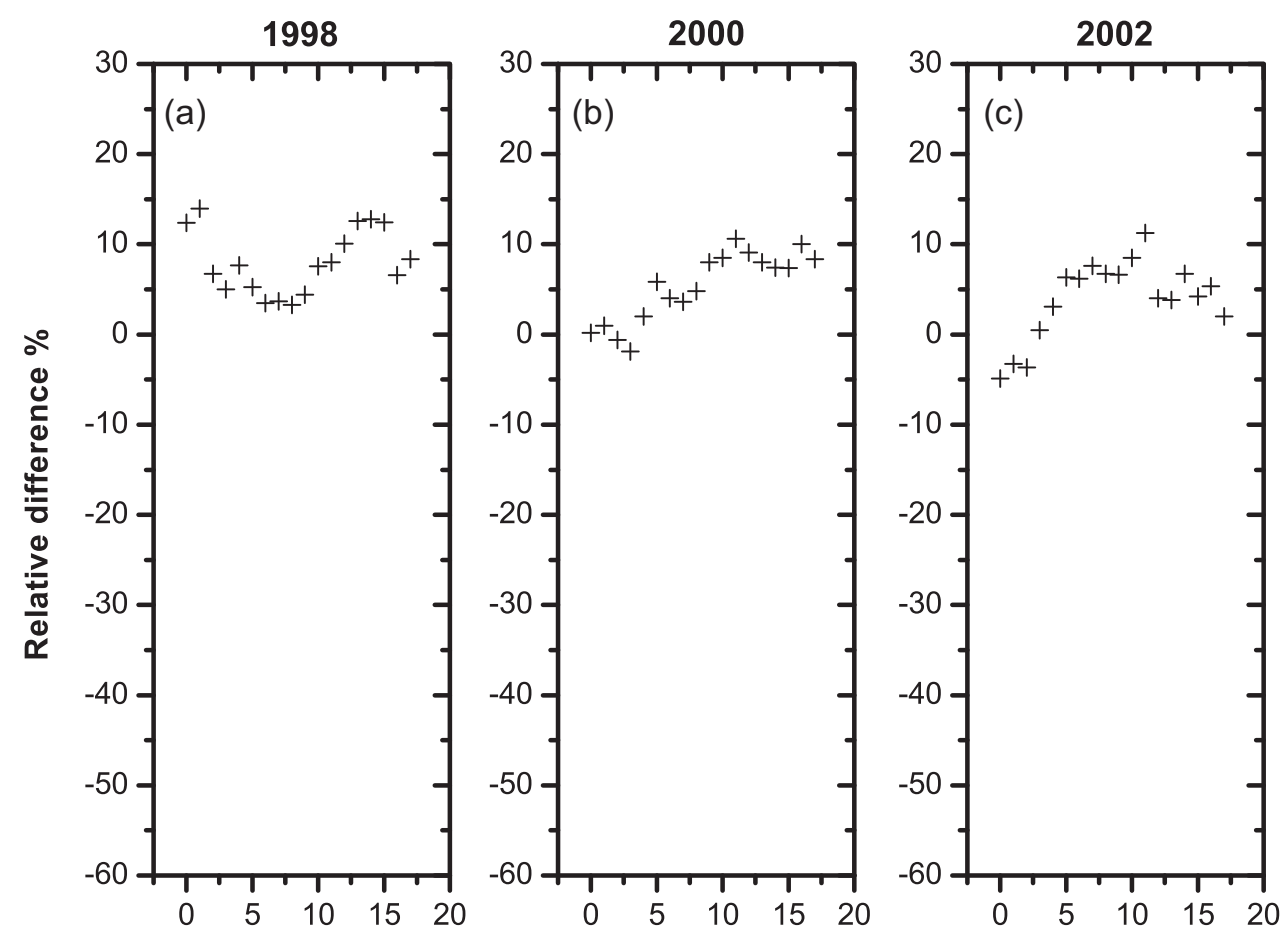

\section{Rigidity cut-off [GV]}

Fig. A.4. Relative difference between computed effective dose $E$ at the altitude of $35 \mathrm{kft}$ a.s.1. and reference data (Menzel 2010). (a) January 1998, (b) January 2000, (c) January 2002. 


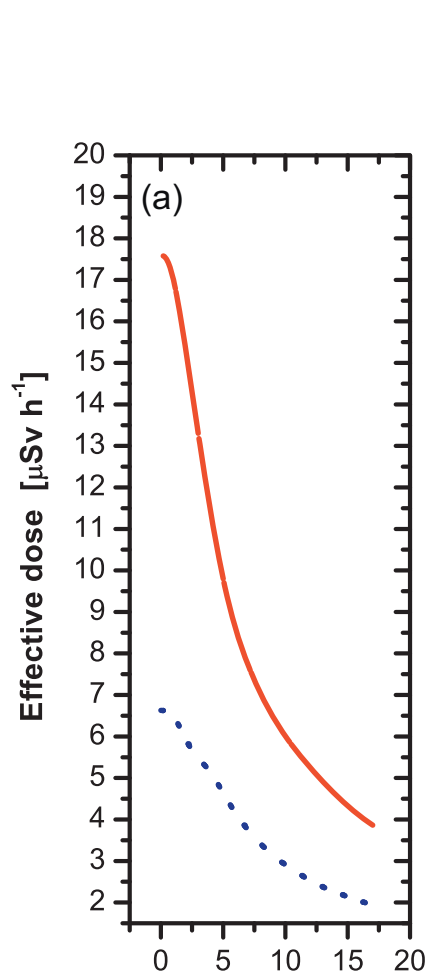

Effective dose rate $50 \mathrm{kft}$

.... Effective dose rate $35 \mathrm{kft}$
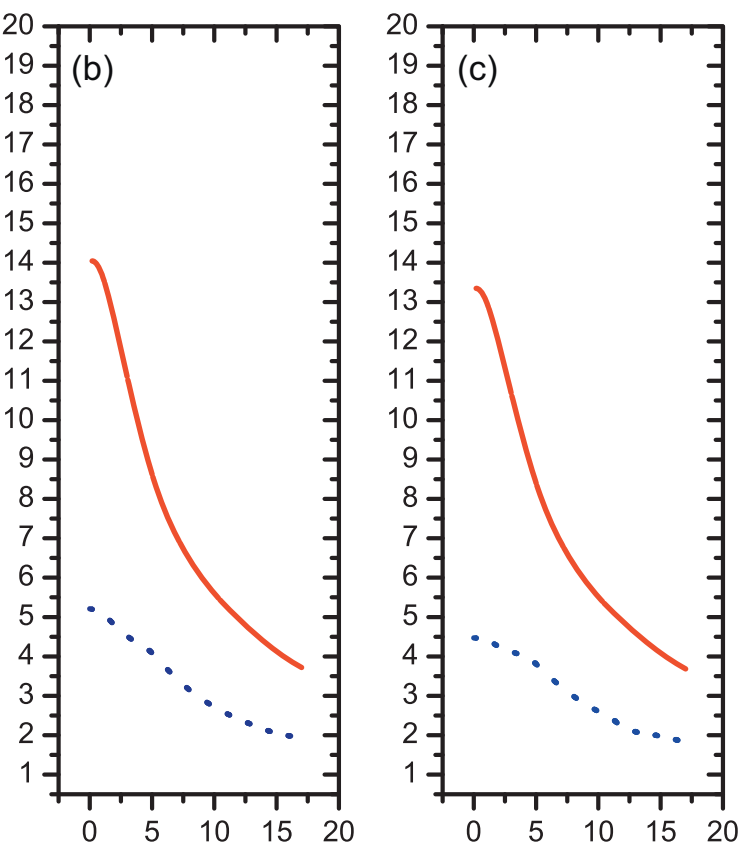

Rigidity cut-off [GV]

Fig. A.5. Computed effective dose rate $E$ at the altitudes of $50 \mathrm{kft}$ a.s.1. and $35 \mathrm{kft}$ a.s.1. (a) January 1998, (b) January 2000 , (c) January 2002.

\section{Appendix B. Spectral and angular characteristics of SEPs during GLE 70 on 13 of December 2006}

Here we use the data from several NM stations for the analysis of the GLE 70 on 13 December 2006. They are given in Table B.2. Most of the data are retrieved from NM database (Mavromichalaki et al. 2011).

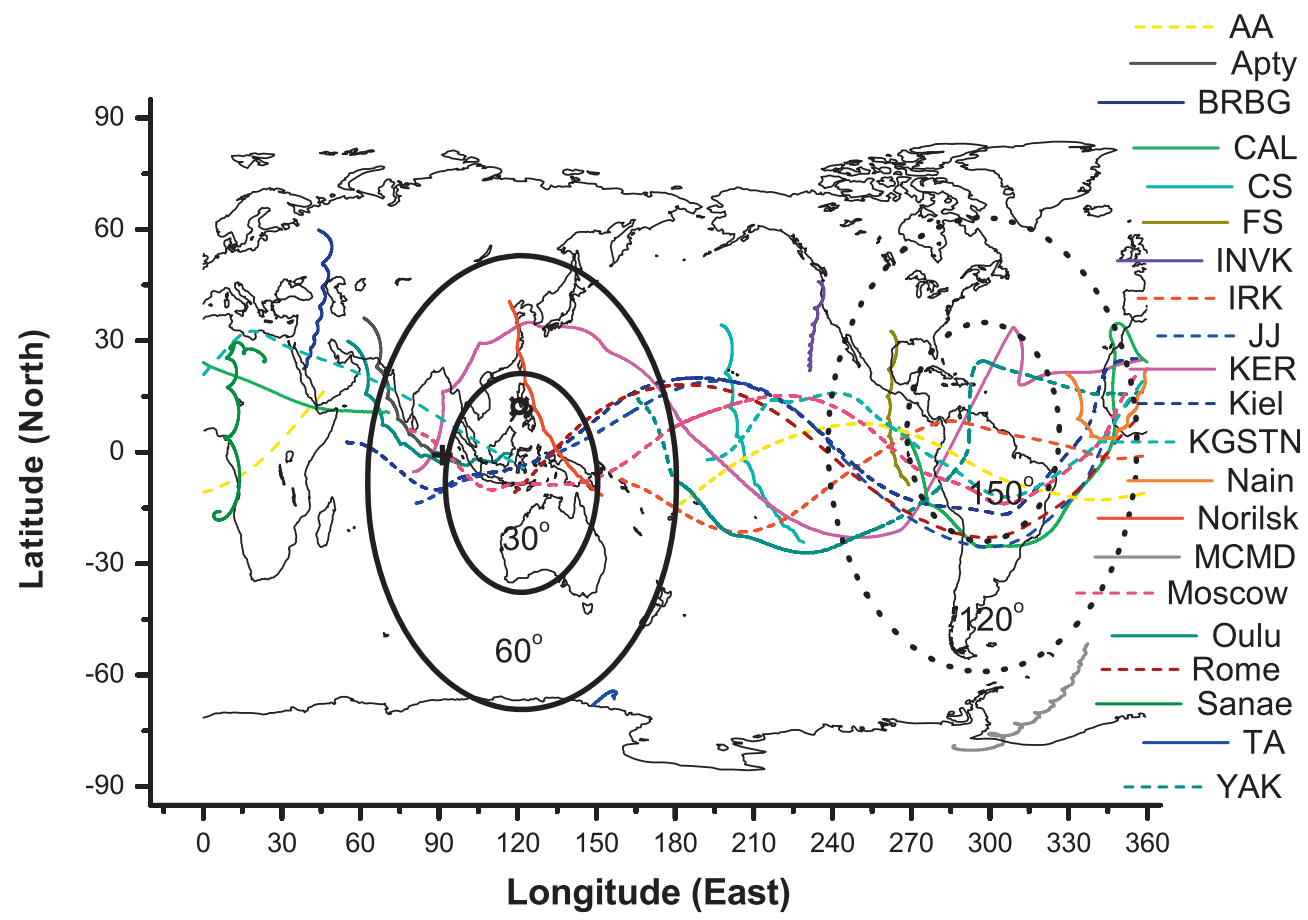

Fig. B.1. Calculated NM asymptotic directions during GLE 70 on 13 December 2006 at 03:00 UT. The cross represents the direction of heliospheric magnetic field (IMF) derived from ACE satellite measurements at 03:00 UT. The small circle represents the derived apparent source position. The lines of equal pitch angles relative to the derived anisotropy axis are plotted for $30^{\circ}, 60^{\circ}, 150^{\circ}$ and $120^{\circ}$. The asymptotic directions of polar NMs are plotted with solid lines, while mid-latitude NMs are plotted with dashed lines. 
A. Mishev and I. Usoskin: Numerical model for computation of effective dose at flight altitudes

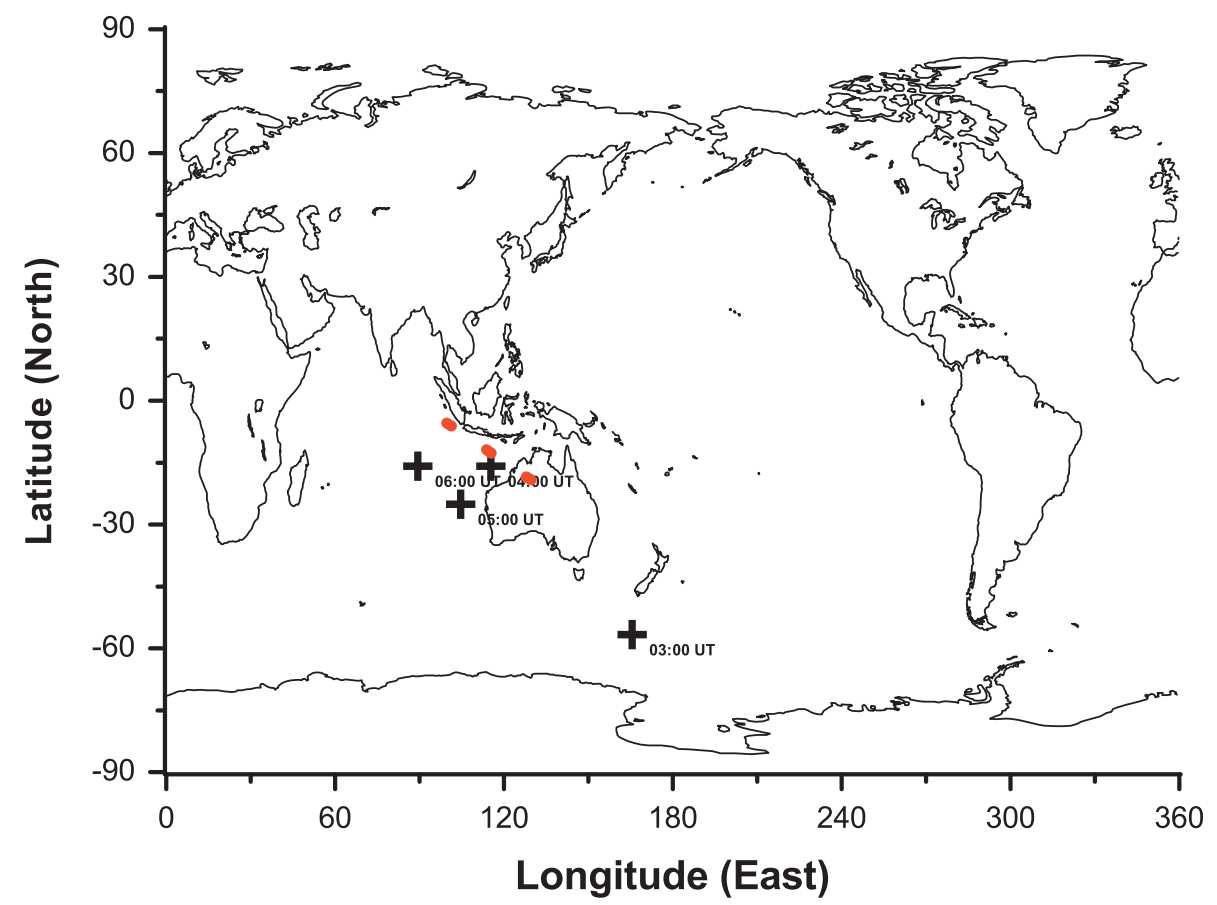

Fig. B.2. Derived apparent source position (red line) and heliospheric magnetic field (crosses) from ACE satellite measurements throughout GLE 70 on 13 December 2006.
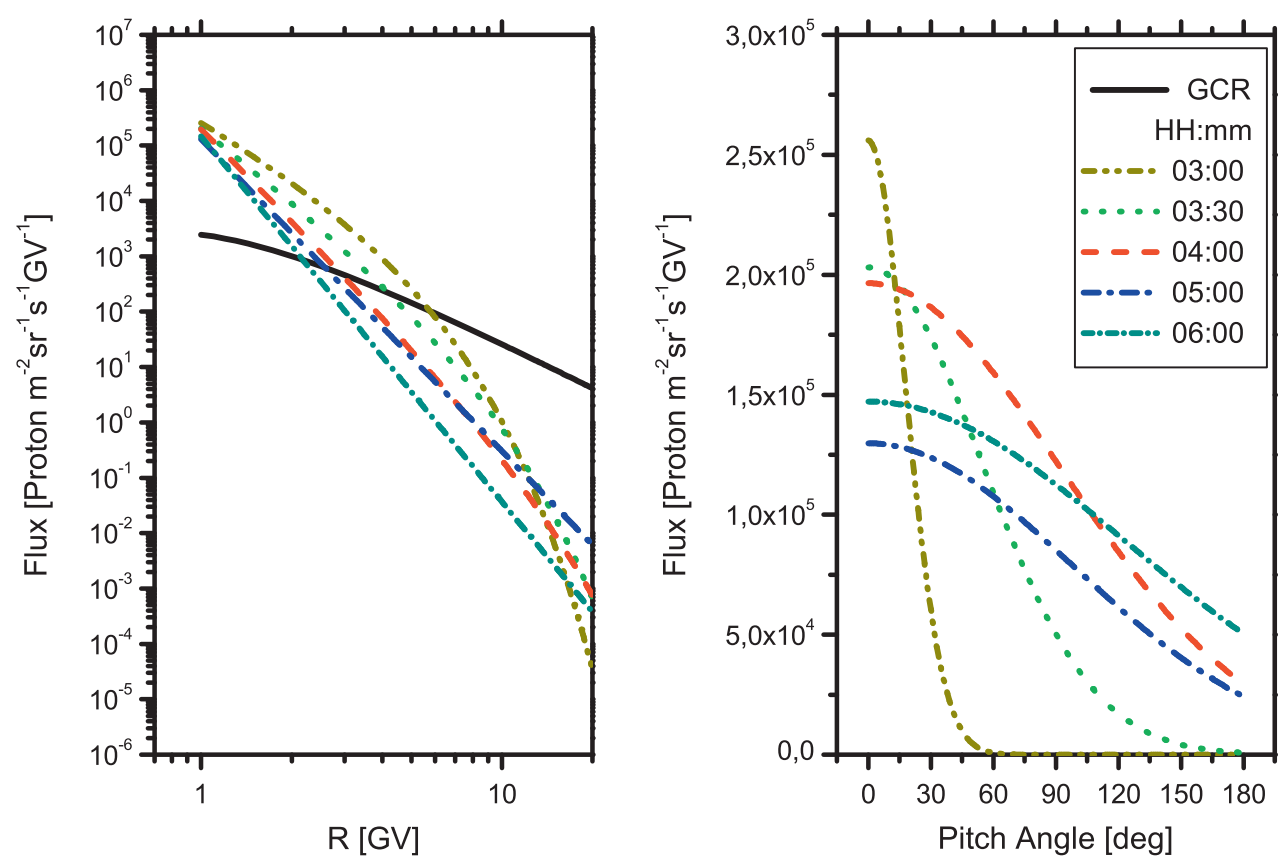

Fig. B.3. The derived spectral and angular characteristics of SEPs for GLE 70 on 13 December 2006 for 03:00 UT throughout 06:00 UT as denoted in the legend.

Table B.1. Derived spectral and angular characteristics for GLE 70 on 13 December 2006.

\begin{tabular}{lllllll}
\hline \hline Time [UT] & $J_{0}$ & $\gamma$ & $\delta \gamma$ & $\sigma_{1}$ & $\Psi$ \\
\hline $03: 05$ & 256,000 & 3.41 & 0.22 & 0.25 & -17 & 148 \\
$03: 30$ & 203,100 & 4.43 & 0.11 & 1.77 & -11 & 131 \\
$04: 00$ & 196,500 & 5.52 & 0.05 & 5.19 & -10 & 120 \\
$05: 00$ & 129,800 & 5.63 & 0 & 5.87 & -8 & 110 \\
$06: 00$ & 147,150 & 6.6 & 0 & 9.2 & -5 & 105 \\
\hline
\end{tabular}


J. Space Weather Space Clim., 5, A10 (2015)

Table B.2. Neutron monitors with corresponding geomagnetic rigidity cut-offs used in the analysis.

\begin{tabular}{|c|c|c|c|c|}
\hline Station & Latitude $\left({ }^{\circ}\right)$ & Longitude $\left({ }^{\circ}\right)$ & $P_{c}(\mathrm{GV})$ & Altitude $(\mathrm{m})$ \\
\hline Alma Ata (AA) & 43.25 & 76.92 & 6.67 & 3340 \\
\hline Apatity (Apty) & 67.55 & 33.33 & 0.48 & 177 \\
\hline Barentsburg (BRBG) & 78.03 & 14.13 & 0 & 70 \\
\hline Calgary (Cal) & 51.08 & 245.87 & 1.04 & 1128 \\
\hline Cape Schmidt (CS) & 68.92 & 180.53 & 0.41 & 0 \\
\hline Forth Smith (FS) & 60.02 & 248.07 & 0.25 & 0 \\
\hline Inuvik (INVK) & 68.35 & 226.28 & 0.16 & 21 \\
\hline Irkutsk (IRK) & 52.58 & 104.02 & 3.23 & 435 \\
\hline Jungfraujoch (JJ) & 46.55 & 7.98 & 4.46 & 3476 \\
\hline Kerguelen (Ker) & -49.35 & 70.25 & 1.01 & 33 \\
\hline Kiel & 54.33 & 10.13 & 2.22 & 54 \\
\hline Kingston (KGSTN) & -42.99 & 147.29 & 1.75 & 65 \\
\hline Lomnicky Štit (LS) & 49.2 & 20.22 & 3.72 & 2634 \\
\hline Magadan (MAG) & 60.12 & 151.02 & 1.84 & 220 \\
\hline McMurdo (MCMD) & -77.85 & 166.72 & 0 & 48 \\
\hline Moscow (MOS) & 55.47 & 37.32 & 2.13 & 200 \\
\hline Nain & 56.55 & 298.32 & 0.28 & 0 \\
\hline Norilsk & 69.26 & 88.05 & 0.52 & 0 \\
\hline Oulu & 65.05 & 25.47 & 0.69 & 15 \\
\hline Peawanuck (PWNC) & 54.98 & 274.56 & 0.16 & 52 \\
\hline Rome & 41.86 & 12.47 & 6.19 & 60 \\
\hline Sanae & -71.67 & 357.15 & 0.56 & 856 \\
\hline Terre Adelie (TA) & -66.67 & 140.02 & 0 & 45 \\
\hline Yakutsk (YAK) & 62.03 & 129.73 & 1.64 & 105 \\
\hline
\end{tabular}

